UNIVERSIDADE DE SÃO PAULO

FACULDADE DE ECONOMIA, ADMINISTRAÇÃO E CONTABILIDADE DE RIBEIRÃO PRETO

DEPARTAMENTO DE CONTABILIDADE

PROGRAMA DE PÓS-GRADUAÇÃO EM CONTROLADORIA E CONTABILIDADE

ROBERTO BLACK

Heterogeneidade no ganho de qualidade informacional com a adoção de IFRS: evidências do Brasil

Orientador: Prof. Dr. Sílvio Hiroshi Nakao 
Prof. Dr. Marco Antônio Zago Reitor da Universidade de São Paulo

Prof. Dr. Dante Pinheiro Martinelli

Diretor da Faculdade de Economia, Administração e Contabilidade de Ribeirão Preto

Profa. Dra. Maísa de Souza Ribeiro

Coordenadora do Programa de Pós-Graduação em Controladoria e Contabilidade

Profa. Dra. Adriana Maria Procópio de Araújo

Chefe de Departamento de Contabilidade 


\section{ROBERTO BLACK}

HETEROGENEIDADE NO GANHO DE QUALIDADE INFORMACIONAL COM A ADOÇÃO DE IFRS: EVIDÊNCIAS DO BRASIL

Dissertação apresentada ao Programa de PósGraduação em Controladoria e Contabilidade da Faculdade de Economia, Administração e Contabilidade de Ribeirão Preto da Universidade de São Paulo como requisito para obtenção do título de Mestre em Controladoria e Contabilidade.

Orientador: Prof. Dr. Sílvio Hiroshi Nakao 
AUTORIZO A REPRODUÇÃO E DIVULGAÇÃO, TOTAL OU PARCIAL, DESTE TRABALHO, POR QUALQUER MEIO, CONVENCIONAL OU ELETRÔNICO PARA FINS DE ESTUDO E PESQUISA, DESDE QUE CITADA A FONTE.

FICHA CATALOGRÁFICA

BLACK, Roberto,

Heterogeneidade no ganho de qualidade informacional com a adoção de IFRS: evidências do Brasil.

Ribeirão Preto, 2015.

Dissertação de Mestrado, apresentada à Faculdade de Economia, Administração e Contabilidade de Ribeirão Preto da Universidade de São Paulo.

Orientador: Prof. Dr. Sílvio Hiroshi Nakao

1. IFRS. 2. Incentivos Econômicos. 3. Qualidade da informação contábil. 


\section{FICHA DE APROVAÇÃO}

BLACK, Roberto.

Título: Heterogeneidade no ganho de qualidade informacional com a adoção de IFRS: evidências do Brasil

Dissertação apresentada ao Programa de PósGraduação em Controladoria e Contabilidade da Faculdade de Economia, Administração e Contabilidade de Ribeirão Preto da Universidade de São Paulo como requisito para obtenção do título de Mestre em Controladoria e Contabilidade.

Aprovado em:

Banca Examinadora

Prof. Dr. Instituição:

Julgamento: Assinatura:

Prof. Dr. Instituição:

Julgamento: Assinatura:

Prof. Dr. Instituição:

Julgamento: Assinatura: 


\section{Agradecimentos}

Agradeço a todos que contribuíram para a realização deste trabalho.

Agradeço a Deus, por me dar saúde e capacidade para concluir esta tarefa.

À minha mãe Ana, meu pai Gilberto e meus irmãos Felipe e Gabriel.

Ao Prof. Dr. Sílvio Hiroshi Nakao, meu orientador, exemplo de caráter e profissionalismo, pelo aprendizado transmitido e suporte ao longo do desenvolvimento da pesquisa.

Aos professores Dr. Rodrigo Verdi, Dr. Antonio Lopo Martinez e Dr. Bruno Meirelles Salotti, membros da banca, pela pronta disposição em participar das bancas de qualificação e defesa e pelas valiosas críticas e sugestões que contribuíram para esta dissertação.

Ao Prof. Dr. Marcelo Botelho da Costa Moraes pelo suporte e auxílio metodológico que me foram prestados no Fórum de pesquisa.

À Coordenação do Programa de Pós-Graduação em Controladoria e Contabilidade da FEARP, nas pessoas da Prof. ${ }^{a}$ Dr. ${ }^{a}$ Maísa de Souza Ribeiro, do Prof. Dr. André Carlos Busanelli de Aquino, e do Prof. Dr. Vinicius Aversari Martins, por toda dedicação ao curso.

Aos demais professores da FEA-RP, pelos preciosos ensinamentos transmitidos, especialmente os professores Dr. Davi Rogério de Moura Costa, Dr. Carlos Alberto Grespan Bonacim, Dr. Sigismundo Bialoskorski Neto, Dr. Fabiano Guasti Lima, Dr. Francisco Anuatti Neto, Dr. Rudinei Toneto Junior e Dr. Sergio Naruhiko Sakurai.

Agradecimento especial a CAPES e a FAPESP que me apoiaram desde o início desta jornada acadêmica.

Agradeço aos meus colegas do mestrado, especialmente à Paola, Gabryel, Bethânia, Juliana, André, Victor, Regiane e Fabiana.

Aos funcionários da FEA-RP que me ajudaram durante toda minha jornada. 


\section{RESUMO}

BLACK, R. Heterogeneidade no ganho de qualidade informacional com a adoção de IFRS: evidências do Brasil. 2015. 81 f. Dissertação (Mestrado) - Faculdade de Economia, Administração e Contabilidade de Ribeirão Preto, Universidade de São Paulo, Ribeirão Preto, 2015.

Esse trabalho tem como objetivo investigar a existência de heterogeneidade no ganho de qualidade informacional com a adoção de IFRS. A adoção de IFRS está geralmente associada com um aumento de qualidade das demonstrações contábeis. Entretanto, as empresas dentro de um mesmo país provavelmente possuem diferentes incentivos econômicos em relação à divulgação da informação. Nesse sentido, tratar as empresas de forma homogênea, sem considerar os incentivos econômicos atrelados, poderia contaminar a investigação da qualidade informacional. É analisado o caso do Brasil, um país classificado como code-law, cuja legislação fiscal induzia a prática contábil e cuja adoção de IFRS foi mandatória. Em primeiro lugar, as empresas brasileiras listadas na BOVESPA foram separadas em dois grupos, a saber: as empresas que emitiram ADR até a adoção de IFRS e as empresas que não emitiram ADR até a adoção de IFRS. Em seguida, esse segundo grupo de empresas foi agrupado, por meio de uma análise de conglomerados, em dois diferentes subgrupos em função de incentivos econômicos em comum. Com base nos grupos identificados, é testada a qualidade da informação contábil para cada grupo antes e após a adoção de IFRS. Esse trabalho utiliza o reconhecimento tempestivo dos eventos econômicos, a value relevance do lucro contábil e o gerenciamento de resultados como proxies para verificar a qualidade da informação contábil. Os resultados encontrados sugerem que um determinado conjunto de empresas obteve, de fato, um incremento de qualidade da informação contábil divulgada após adoção do padrão IFRS no Brasil. Esse grupo de empresas teria incentivos suficientes para deixar para trás a conformidade contábil-fiscal e apresentar uma qualidade superior no seu conjunto de informações contábeis divulgadas. Além disso, foi verificado um segundo grupo de empresas com qualidade da informação contábil antes e após 2008. Em contrapartida, foi identificado um terceiro conjunto de empresas que não apresentou qualidade da informação contábil seja antes ou após 2008. Esses resultados corroboram o pressuposto de que os incentivos no nível das empresas possuem um papel relevante na qualidade das demonstrações contábeis. Isso não implica afirmar que as normas contábeis não importam, mas de que existem outros direcionadores que moldam a qualidade das demonstrações contábeis e que as normas contábeis deveriam ser vistas como um desses direcionadores.

Palavras-chave: IFRS, incentivos econômicos, qualidade da informação. 


\begin{abstract}
BLACK, R. Heterogeneity in accounting quality after the adoption of IFRS: evidence from Brazil. 2015. 81 f. Dissertação (Mestrado) - Faculdade de Economia, Administração e Contabilidade de Ribeirão Preto, Universidade de São Paulo, Ribeirão Preto, 2015.

This work aims to investigate the existence of heterogeneity in the quality of accouting information after the adoption of IFRS. The adoption of IFRS is generally associated with an increased quality of the financial statements. However, companies within the same country probably have different economic incentives regarding the disclosure of information. Accordingly, treat companies evenly, without considering the linked economic incentives, could contaminate the identification of information quality after the adoption of IFRS. It examined the case of Brazil, a country classified as code-law, whose tax laws induced the accounting practice and whose adoption of IFRS is mandatory. First, Brazilian companies listed on the BOVESPA were separated into two groups, namely: companies issuing ADRs to the adoption of IFRS and the companies that have not issued ADR to the adoption of IFRS. Then, this second group of companies were grouped by means of a cluster analysis in two different subgroups based on economic incentives in common. Then, based on the identified groups, the accounting quality information is tested for each group before and after the adoption of IFRS. This work uses the timely recognition of economic events, value relevance of net income and earnings management as proxies for the quality of accounting information. The results suggest that a particular group of companies obtained, in fact, an increase of accounting information quality after adoption of the IFRS in Brazil. This group of companies would have sufficient incentives to leave behind the accounting and tax compliance and provide superior quality to your set of accounting information disclosed. In addition, a second group of companies with quality of accounting information was checked before and after 2008. In contrast, a third group of companies has been identified that did not show quality of accounting information either before or after 2008. These results support the assumption that incentives at the level of companies have an important role in the quality of financial statements. This does not imply stating that accounting standards do not matter, but that there are other drivers that shape the quality of financial statements and accounting standards should be seen as one of those drivers.
\end{abstract}

Keywords: IFRS, firm-level incentives, accounting quality. 


\section{LISTA DE TABELAS}

Tabela 1 - Amostra para o Modelo Reverso de Lucros Associados a Retornos (2003 a 2007)

Tabela 2 - Amostra para o Modelo Reverso de Lucros Associados a Retornos (2008 a 2014)

Tabela 3 - Amostra para o modelo de Accruals Discricionários de Kothari, Leone e Wasley (2005) de 2005 a 2007 42

Tabela 4 - Amostra para o modelo de Accruals Discricionários de Kothari, Leone e Wasley (2005) de 2008 a 2014

Tabela 5 - Amostra para o modelo de Value Relevance para o Modelo de Retorno (2003 a 2007).

Tabela 6 - Amostra para o modelo de Value Relevance para o Modelo de Retorno (2008 a 2014)

Tabela 7 - Tabela de correlação entre as variáveis de agrupamento ........................................46

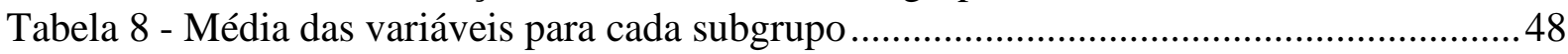

Tabela 9 - Estatística descritiva das variáveis de agrupamentos para os grupos serious

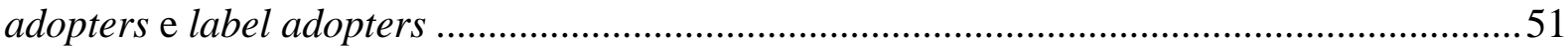

Tabela 10 - Regressões para o Modelo Reverso de Lucros Associados a Retornos para os três grupos de empresas no período de 2003 a 2007.................................................................52 Tabela 11 - Regressões para o modelo de Value Relevance para os três grupos de empresas no

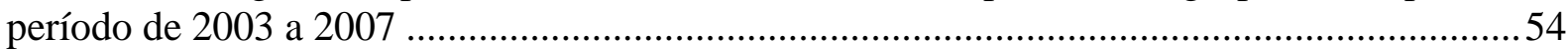
Tabela 12 - Regressões para o Modelo Reverso de Lucros Associados a Retornos para os três grupos de empresas no período de 2008 a 2014 .........................................................................56 Tabela 13 - Estatística descritiva dos accruals discricionários para os três grupos de empresas antes e após 2008 .

Tabela 14 - Teste ANOVA da distribuição dos accruals discricionários para os três grupos de

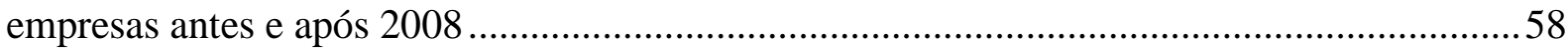

Tabela 15 - Regressões para o modelo de accruals discricionários para os três grupos de

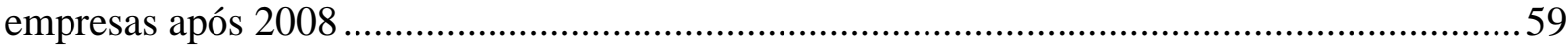

Tabela 16 - Regressões para os modelos de Value Relevance para os três grupos de empresas no período de 2008 a 2014

Tabela 17 - Regressão para o Modelo Reverso de Lucros Associados a Retornos para o grupo ADR e para o grupo serious adopters no período de 2008 a 2014

Tabela 18 - Regressões para o modelo de Value Relevance para o grupo ADR e para o grupo serious adopters no período de 2008 a 2014. 64 Tabela 19 - Regressões para o Modelo Reverso de Lucros Associados a Retornos para os três grupos de empresas no período de 2008 a 2014, incluindo a dummy RTT. . .66 Tabela 20 - Regressões para os modelos de Value Relevance para os três grupos de empresas no período de 2008 a 2014, incluindo a dummy RTT 


\section{LISTA DE SIGLAS}

ADR - American Depositary Receipt

ANEFAC - Associação Nacional dos Executivos de Finanças, Administração e Contabilidade

BCB - Banco Central do Brasil

CFC - Conselho Federal de Contabilidade

CSSL - Contribuição Social sobre o Lucro Líquido

CVM - Comissão de Valores Mobiliários

ETR - Effective Tax Rate

GAAP - Generally Accepted Accounting Principles

IAS - International Accounting Standards

IBRACON - Instituto dos Auditores Independentes do Brasil

IFRS - International Financial Reporting Standards

IRPJ - Imposto de Renda Pessoa Jurídica

PCGA - Princípios Contábeis Geralmente Aceitos

RTT - Regime Tributário de Transição 


\section{SUMÁRIO}

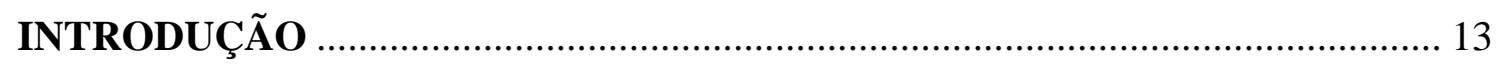

1. REVISÃO DA LITERATURA E DESENVOLVIMENTO DA HIPÓTESE . 18

1.1 QUALIDADE DA INFORMAÇÃO CONTÁBIL ANTES DA ADOÇÃO DO PADRÃO IFRS.

1.2 QUALIDADE DA INFORMAÇÃO CONTÁBIL APÓS A ADOÇÃO DE IFRS.20

1.3 ASSOCIAÇÃO ENTRE ADOÇÃO DE IFRS E QUALIDADE DA INFORMAÇÃO CONTÁBIL..

1.4 CARACTERÍSTICAS INSTITUCIONAIS E SEU IMPACTO SOBRE A QUALIDADE

DA INFORMAÇÃO CONTÁBIL ...................................................................... 23

1.5 INCENTIVOS ECONÔMICOS NO NÍVEL DA EMPRESA ................................ 26

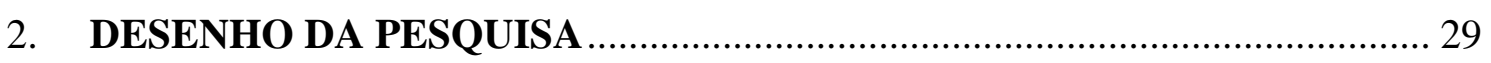

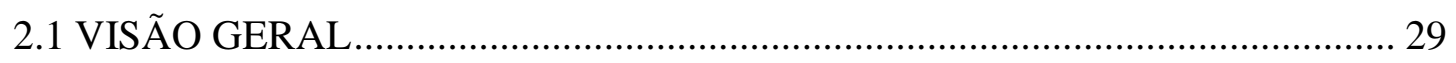

2.2 AGRUPAMENTO DE EMPRESAS COM DIFERENTES QUALIDADES DA INFORMAÇÃO CONTÁBIL ANTES DA ADOÇÃO DE IFRS …………………... 29

2.3 AGRUPAMENTO DE EMPRESAS COM INCENTIVOS ECONÔMICOS

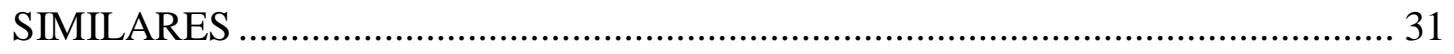

2.4 MEDIDAS DE QUALIDADE DA INFORMAÇÃO CONTÁBIL ....................... 34

2.4.1 Teste de Conservadorismo Condicional ………………………………….... 34

2.4.1.1 Modelo Reverso de Lucros Associados a Retornos ....................................... 35

2.4.2 Teste de Gerenciamento de Resultados .................................................... 38

2.4.2.1 Modelo de Accruals Discrionários de Kothari, Leone e Wasley (2005)........ 38

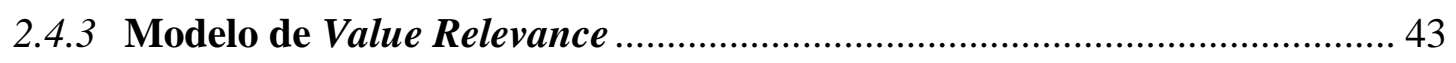

2.4.3.1 Especificação do Modelo de Retorno ................................................................. 43

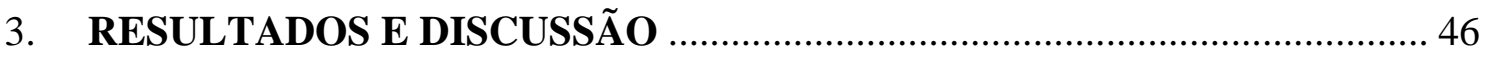

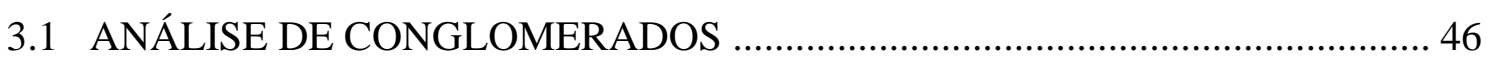

3.1.1 Tabela de Correlação ………………………………..................................... 46

3.1.2 Análise de Cluster ....................................................................................... 47

3.1.3 Estatística descritiva das variáveis de agrupamento ………………………..... 50

3.2 RESULTADOS PARA OS TESTES DE QUALIDADE DA INFORMAÇÃO

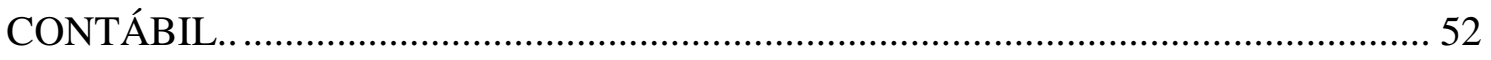

3.2.1 Resultados para o Modelo Reverso de Lucros Associados a Retornos para os três grupos de empresas antes da adoção de IFRS 
3.2.2 Resultados para o Modelo de Value Relevance para os três grupos de empresas

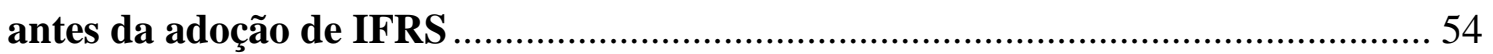

3.2.3 Resultados para o Modelo Reverso de Lucros Associados a Retornos para os três grupos de empresas após a adoção do IFRS 55

3.2.4 Resultado para o Modelo de Accruals Discricionários de Kothari, Leone e Wasley (2005) para os três grupos de empresas após a adoção do IFRS

3.2.5 Resultados para o modelo de Value Relevance para os três grupos de empresas após a adoção do IFRS 60

3.2.6 Testes de Robustez. 62

3.2.6.1 Análise conjunta dos grupos que apresentam qualidade da informação contábil após a adoção do padrão IFRS 62

3.2.6.1.1 Resultados para o Modelo Reverso de Lucros Associados a Retornos e Value Relevance para o grupo ADR e para o grupo serious adopters no período de 2008 a 2014. .63

3.2.6.2 Efeito da desvinculação tributária sobre o ganho de qualidade após a adoção do IFRS. 


\section{INTRODUÇÃO}

A adoção de IFRS (International Financial Reporting Standards) está normalmente associada com o aumento da qualidade da informação contábil divulgada (BARTH, LANDSMAN e LANG, 2008). Argumentos sugerindo que a adoção de IFRS produz benefícios significativos para o mercado de capitais partem da premissa de que a divulgação em IFRS aumenta a transparência e aumenta a qualidade das demonstrações financeiras. Isso reflete o fato do padrão IFRS ser mais orientado ao mercado de capitais e mais abrangente, especialmente no que diz respeito ao disclosure, em relação a grande parte dos PCGA (Princípios Contábeis Geralmente Aceitos) nacionais.

Entretanto, há também argumentos sugerindo que os efeitos da adoção de IFRS no mercado de capitais poderiam ser pequenos ou até mesmo insignificantes. Em particular, há razões para ser cético em relação à premissa de que a adoção de IFRS per se torna as demonstrações financeiras com maior conteúdo informacional ou até mesmo mais comparáveis (DASKE, HAIL, LEUZ e VERDI, 2008). A evidência em diversos estudos aponta para o papel limitado das normas contábeis em determinar a qualidade contábil observada e, pelo contrário, enfatiza a importância dos incentivos na divulgação contábil das empresas (BALL, KOTHARI e ROBIN, 2000; BALL, ROBIN e WU, 2003; LEUZ, 2003; BALL e SHIVAKUMAR, 2005; BURGSTAHLER, HAIL e LEUZ, 2006).

Daske et al. (2008) argumentam que os efeitos do mercado de capitais em torno da introdução da adoção mandatória de IFRS não são uniformemente distribuídos entre países e empresas. Os autores encontram que os efeitos no mercado quando da adoção mandatória de IFRS ocorrem apenas em países com um forte mecanismo de enforcement $\mathrm{e}$ onde o ambiente institucional fornece fortes incentivos para que as empresas sejam transparentes. Esses resultados são consistentes com a visão de que a convergência às normas internacional é provavelmente heterogênea entre países (BALL, 2006), e com a ideia de que os incentivos de divulgação das empresas, que são moldados pelos mercados e pelos ambientes institucionais desses países, possuem um 
papel crucial nas demonstrações financeiras (BALL, ROBIN e WU, 2003; BALL e SHIVAKUMAR, 2005; BURGSTAHLER, HAIL, e LEUZ, 2006).

Nesse sentido, a adoção do padrão IFRS pode não ser vista como uma condição suficiente para que as empresas de um mesmo país alcancem um incremento de qualidade. É esperada, então, a existência de heterogeneidade no ganho de qualidade informacional. Em outras palavras, é possível que determinados grupos de empresas alcancem um ganho informacional em função de incentivos econômicos, ao passo que outros grupos de empresas não alcancem um incremento de qualidade mesmo quando da adoção do IFRS. As empresas com maiores incentivos de divulgação possuiriam maior monitoramento do mercado acionário, que por sua vez estaria associado com os investidores demandando informação de maior qualidade.

Assim, este estudo pretende responder à seguinte questão de pesquisa: existe heterogeneidade no ganho de qualidade informacional entre empresas com a adoção de IFRS?

É analisado o caso do Brasil. O Brasil é um país de tradição code-law, com adoção mandatória de IFRS e cuja legislação fiscal induzia a prática contábil até a quebra da conformidade contábil-fiscal em 2007.

A quebra da ligação formal entre as normas contábeis brasileiras para fins de divulgação e as regras tributárias ocorreu com a publicação da Lei 11.638 em 2007. Além disso, a Lei 11.638 teve como objetivo atualizar a legislação societária para possibilitar o processo de convergência das práticas contábeis adotadas no Brasil. Assumiu-se que esses dois eventos foram relevantes para a redução da dependência de trajetória do reporte financeiro em relação às regras tributárias, porque as companhias começaram a ser capazes de fazer mudanças que não eram possíveis anteriormente.

Além disso, destaca-se o fato de a adoção do padrão IFRS no Brasil ser realizada de maneira mandatória. A CVM (Comissão de Valores Mobiliários) optou por adotar uma estratégia de transição gradual (composta por duas fases) para o novo padrão, exigindo a adoção de algumas normas para o exercício de 2008 e determinando a convergência completa com o IFRS para todas as companhias abertas em 2010. A adoção mandatória das normas internacionais não, necessariamente, conduz a informação contábil de 
elevada qualidade, pelo menos para àquelas empresas que não tem incentivos para adotar. Visto de outra forma, se fosse estabelecida a adoção voluntária do IFRS, as empresas com menores incentivos de divulgação dificilmente adotariam o padrão IFRS no primeiro ano de publicação. Em função das empresas encararem diferentes incentivos de divulgação dentro do mesmo país, é natural supor que a qualidade da informação contábil também seja heterogênea.

Para responder à pergunta de pesquisa, foram testados conservadorismo condicional, value relevance e gerenciamento de resultado para três grupos de empresas com diferentes incentivos econômicos para divulgação da informação contábil.

O primeiro grupo de empresas foi denominado serious adopters. Com adoção das normas internacionais e com a desvinculação das normas tributárias, conjectura-se que um grupo de empresas passou por um incremento de qualidade com a adoção do padrão IFRS. Essas empresas teriam incentivos econômicos suficientes para deixar para trás a conformidade contábil-fiscal e apresentar uma qualidade superior no seu conjunto de informações contábeis divulgadas.

Esse conjunto de empresas consideraria a adoção de IFRS como uma oportunidade para fornecer informação de maior qualidade para o mercado e aumentar o grau de transparência das informações contábeis. Alguns motivos para a empresa ver a adoção de IFRS como uma oportunidade é o fato da empresa estar entrando recentemente no mercado de ações ou ter aspirações para realizar novas captações. Além disso, a própria vinculação entre as normas para fins de divulgação e para fins fiscais poderia ser vista como um obstáculo para essas empresas adotarem uma informação de maior qualidade.

Daske, Hail, Leuz e Verdi (2013) apontam que empresas maiores, com maior necessidade de obtenção de recursos, com maior oportunidade de crescimento e com um menor nível de concentração acionária possuem maiores incentivos em fornecer uma informação mais transparente. Essas variáveis foram utilizadas, por meio de uma análise de conglomerados, para identificar empresas com incentivos econômicos em fornecer uma informação contábil de maior qualidade.

O segundo grupo foi denominado $A D R$. Conjectura-se que as empresas brasileiras com ADR (American Depositary Receipt) possuíam qualidade superior antes 2008. O menor 
desenvolvimento do mercado de capitais brasileiro levou as empresas nacionais, com oportunidades de crescimento, a buscarem financiamento externo. Somado ao fato do mercado norte americano ser mais exigente em relação à transparência e demandar informação contábil de maior qualidade, é predito que o grupo de empresas brasileiras que emitiu ADR possuiria maior qualidade da informação contábil mesmo antes de 2008. Argumenta-se, porém, que esse grupo de empresas não sofreria mudanças significativas na qualidade da informação contábil após a adoção das normas internacionais de contabilidade. Em outras palavras, não é esperado um incremento significativo de qualidade da informação contábil, pois essas empresas já vinham adotando práticas e políticas contábeis mais próximas das normas internacionais de contabilidade.

Além disso, argumenta-se que existia um grupo de empresas com qualidade inferior, mas que não alcançariam um incremento de qualidade informacional com a adoção de IFRS. Esse grupo foi denominado de label adopters. Argumenta-se que empresas com baixo monitoramento do mercado de ações podem não exibir melhorias em termos de qualidade das informações para divulgação nos períodos seguintes à adoção de IFRS em função de dependência de trajetória (path dependence) ligada à tributação.

Os resultados obtidos com os testes de conservadorismo condicional e value relevance indicam que o grupo serious adopters realmente passou a exibir qualidade da informação contábil após a adoção do padrão IFRS. Em contrapartida, o grupo label adopters não exibiu melhoria de qualidade da informação contábil após a adoção do IFRS. Já o grupo ADR possui conservadorismo condicional e value relevance do lucro contábil tanto antes quanto após a adoção do IFRS.

Esse trabalho procura contribuir com a literatura sobre o processo de adoção de IFRS, particularmente, em países emergentes. Mais especificamente, esse trabalho procura superar a limitação dos estudos empíricos nacionais que tendem a focar no efeito médio da adoção de IFRS. Assim, a verificação e a investigação de cada um dos três grupos e suas particularidades podem ser vistas como a principal contribuição desse trabalho.

Além disso, a verificação de três diferentes grupos, em um mesmo país, no que diz respeito à qualidade da informação contábil pode ser útil aos órgãos normatizadores 
nacionais e internacionais, tendo em vista os recentes esforços desses órgãos em consolidar a convergência das normas contábeis no nível internacional. Os resultados sugerem que um conjunto global e uniforme de normas contábeis podem não ter ser suficiente para fazer com que as propriedades nos números contábeis convirjam para um mesmo nível. Dessa forma, os resultados encontrados podem servir como subsídio para tomada de decisões dos órgãos normatizadores.

O trabalho é estruturado como segue: no próximo capítulo é feita uma revisão da literatura e o desenvolvimento da hipótese; no capítulo 2 são apresentadas as amostras, as medidas das variáveis e os testes empíricos; no capítulo 3 são apresentados os resultados e no último capítulo as considerações finais. 


\section{REVISÃO DA LITERATURA E DESENVOLVIMENTO DA HIPÓTESE}

\subsection{QUALIDADE DA INFORMAÇÃO CONTÁBIL ANTES DA ADOÇÃO DO PADRÃO IFRS}

Até a aprovação da Lei n. 11.638/07, o sistema contábil no Brasil estava de certa forma, ligado à apuração do imposto de renda. A Secretaria da Receita Federal do Brasil (SRF), por meio do Decreto-Lei n. 1.598/77, vinculou a legislação fiscal à legislação societária (Lei n. 6.404/76) ao estabelecer a apuração do lucro tributável a partir do lucro contábil considerando alguns ajustes definidos pela legislação tributária.

Apesar de a Lei n. 6.404/76 prever que a escrituração contábil deveria ser efetuada com base nos PCGA e que as diferenças encontradas entre as legislações fiscais e societárias deveriam ser tratadas de forma extra contábil no Livro de Apuração do Lucro Real (LALUR), havia uma influência fiscal indireta direcionando as empresas a não utilizarem os critérios contábeis. As empresas, por vezes, abandonavam práticas contábeis consideradas mais adequadas sob o ponto de vista da contabilidade societária para não ter que, com isso, adiantar o pagamento de tributos. Isso ocorria, por exemplo, com a depreciação. Caso a vida útil econômica de um ativo fosse menor do que o período mínimo permitido para dedução fiscal, a empresa deveria seguir as taxas de depreciação da legislação fiscal para fins de dedutibilidade. Entretanto, se a vida útil econômica de um ativo fosse maior, a autoridade fiscal exigiria a utilização dessa taxa para fins de dedutibilidade da base de cálculo do imposto de renda.

Além disso, o Brasil possuía todas as características usualmente associadas com uma divulgação contábil de baixa qualidade - baixo enforcement legal, elevada participação do governo nas normas contábeis, alta participação do Estado na economia, financiamento predominantemente bancário, mercados de títulos pouco desenvolvido, incentivos para manipular os lucros tendo em vista a proximidade entre a divulgação para fins financeiros e fins fiscais e um mercado financeiro altamente volátil e instável com padrões de governança que deixavam a desejar (ALI e HWANG, 2000; BALL et 
al, 2000; 2003). Nesse sentido, o Brasil seria um típico país de tradição Code-Law em que as demonstrações financeiras não seriam preparadas para informar os investidores, mas para estar de acordo com as exigências fiscais e regulatórias.

Portanto, não existia uma distinção clara entre regras fiscais e normas contábeis para fins de divulgação financeira na prática, antes da adoção de IFRS. Poder-se-ia afirmar que a legislação fiscal induzia a prática contábil.

Entretanto, mesmo em um ambiente de baixa qualidade da informação contábil e frágil regime de governança como o Brasil, algumas empresas poderiam enfrentar fortes incentivos para afastar-se do ambiente de baixa qualidade de seu país com o objetivo de financiar futuros projetos de investimento (LOPES e WALKER, 2008). Empresas com oportunidades de crescimento estavam mais propensas a buscar capital estrangeiro, uma vez que o mercado interno era visto como relativamente pequeno e fortemente baseado no crédito bancário. Nesse sentido, empresas com oportunidades de investimento desejando obter financiamento externo possuíam fortes incentivos para aumentar a qualidade de seus demonstrativos financeiros, tendo em vista uma maior demanda desses mercados por informação de maior qualidade.

Dessa forma, mesmo antes da adoção do padrão IFRS é possível que exista um grupo de empresas que apresentava informação contábil com qualidade superior. Lopes e Walker (2008) encontram uma relação estatisticamente significante entre o grau de governança e a redução do gerenciamento de resultados de empresas com ADRs. Os resultados para empresas que recebem ao mesmo tempo bons níveis de governança e emitem títulos internacionalmente são comparáveis com o que foi encontrado para empresas em países desenvolvidos com regime Code-Law. Esses resultados sugerem que empresas imersas no frágil sistema contábil e de governança brasileiro podem apresentar informação de alta qualidade, mesmo antes da adoção de IFRS, se elas possuírem os incentivos apropriados.

Portanto, antes da adoção das normas internacionais, é possível destacar a existência de dois grupos que diferiam em relação à qualidade da informação contábil divulgada. $\mathrm{O}$ grupo com qualidade superior seria aquele constituído por aquelas empresas com títulos emitidos no mercado internacional. Em contrapartida, o restante das empresas não sofria 
pressão por parte de investidores e credores em divulgar uma informação contábil de qualidade superior, já que havia uma cultura de que a legislação tributária prevalecia sobre a divulgação contábil. Ou seja, em mercados de capitais com elevada concentração acionária, como o Brasil, empresas com maior concentração acionária possuem outros incentivos econômicos como, por exemplo, a minimização do pagamento de tributos. Nesse sentido, poder-se-ia argumentar que legislação fiscal induzia a prática contábil para esse grupo de empresas.

\subsection{QUALIDADE DA INFORMAÇÃO CONTÁBIL APÓS A ADOÇÃO DE IFRS}

A publicação da Lei 11.638 em 2007 e da Lei 11.941 em 2009 legitimou o processo de convergência contábil, a desvinculação das normas societárias e fiscais, a redução da interferência governamental na emissão de normas societárias e os poderes do Comitê de Pronunciamentos Contábeis (CPC) para elaborar pronunciamentos visando essa convergência (BRASIL, 2007; 2009).

Mais especificamente, a Lei n. 11.638/07 obrigou as sociedades anônimas a adotarem as IFRS para as demonstrações contábeis individuais e consolidadas, com o objetivo de aumentar o grau de transparência das demonstrações financeiras e fortalecer o mercado de capitais atraindo novos investimentos para o país (CPC, 2008). Além disso, essa Lei determina que as normas da CVM devam estar de acordo com as normas internacionais de contabilidade financeira e modificou a Lei 6.404 para deixar claro que a contabilidade financeira deve ser separada da contabilidade tributária.

A Lei $n^{\circ} 11.941 / 09$ reforçou esta segregação ao definir regras sobre ajustes no lucro tributável resultante de diferenças em relação à mensuração do lucro contábil. Ela criou um regime tributário de transição fazendo com que o cômputo do lucro contábil não dependesse mais dos critérios para cômputo do lucro tributável, dando aos gestores a escolha de seguir as regras tributárias para o cômputo do lucro contábil ou não (BRASIL, 2009). 
Com adoção das normas internacionais e com a desvinculação das normas tributárias, é possível que um grupo de empresas, que possuía informação de menor qualidade, passou por um incremento de qualidade com a adoção do padrão IFRS. Empresas com maior monitoramento do mercado acionário poderiam ter incentivos suficientes para deixar para trás a conformidade contábil-fiscal e apresentar maior qualidade no seu conjunto de informações divulgadas.

Essas empresas considerariam a adoção de IFRS como uma oportunidade para fornecer informação de alta qualidade para o mercado e aumentar o grau de transparência da empresa. Alguns motivos para a empresa ver a adoção de IFRS como uma oportunidade é porque ela pode estar entrando recentemente no mercado, ter aspirações para realizar novas captações no mercado de ações ou até mesmo ter necessidade de captar recursos de terceiros com custo mais baixo.

Visto de outra forma, essas empresas não possuíam incentivos econômicos suficientes antes da adoção de IFRS a ponto de, por exemplo, emitir títulos no mercado internacional. Além disso, a própria vinculação entre as normas para fins de divulgação e para fins fiscais poderia ser vista como um obstáculo para essas empresas adotarem uma informação de maior qualidade. Assim, empresas que, por exemplo, estivessem entrando recentemente no mercado passariam a enxergar o padrão IFRS como uma oportunidade para aumentar a qualidade da informação contábil.

Esse grupo de empresas seria o único que enfrentaria uma variação significativa em termos de qualidade da informação contábil. Aquele grupo com qualidade superior antes da adoção de IFRS continuaria engajado em divulgar uma informação contábil de qualidade superior e, portanto, não sofreria mudanças significativas na qualidade da informação contábil. Nesse sentido, Daske et al. (2008) argumentam que é esperado um impacto menor em países onde já existe um qualidade superior da informação contábil ou onde os PCGA locais e IFRS fossem próximos.

Já o grupo de empresas com incentivos econômicos não voltados para a divulgação para o mercado de capitais continuaria com um nível semelhante de similaridade contábilfiscal mesmo após a adoção de IFRS e, assim, não apresentaria incremento de qualidade da informação contábil divulgada. 
Para ilustrar, tomemos como exemplo a depreciação para fins tributários. A legislação do imposto de renda estabelece que um equipamento seja depreciado em pelo menos 10 anos. Algumas empresas brasileiras continuam mantendo os 10 anos como a vida útil de seus equipamentos. Entretanto, é realmente difícil de acreditar que após a revisão da política de depreciação, todos os equipamentos dessas companhias permanecem exatamente com uma vida útil de 10 anos.

Portanto, poderiam ser observadas diferenças na qualidade da informação contábil para empresas aplicando o padrão IFRS por razões que não aquelas associadas à divulgação contábil propriamente dita, mas sim aos incentivos econômicos das empresas. Nesse sentido, é predito que os incentivos no nível das empresas possuem um papel relevante na qualidade das demonstrações contábeis.

\subsection{ASSOCIAÇÃO ENTRE ADOÇÃO DE IFRS E QUALIDADE DA INFORMAÇÃO CONTÁBIL}

A adoção de IFRS está geralmente associada com um aumento de qualidade das demonstrações contábeis. Espera-se que uma maior qualidade dos lucros esteja associada com reconhecimento tempestivo dos eventos econômicos, value relevance de variáveis contábeis e menor gerenciamento de resultados (BARTH, LANDSMAN e LANG, 2008). Os reguladores tem a expectativa de que o uso do padrão IFRS aumente a comparabilidade das demonstrações financeiras, aumente a transparência corporativa, aumente a qualidade das demonstrações financeiras e, assim, seja benéfico para os investidores (Regulamento CE nº 1606/2002).

Espera-se que os lucros tendo como base as normas do IASB sejam menos gerenciados do que se baseados nas normas nacionais, pois o IASB procura limitar o poder discricionário dos gestores em divulgar lucros que não reflitam o desempenho econômico da empresa. Utilizando uma amostra de empresas de 20 países europeus, Aubert e Grudnitski (2012) verificaram que ocorreu uma queda no gerenciamento de resultado após a adoção mandatória de IFRS. Zéghal, Chtourou e Sellami (2011) 
encontraram evidências de redução no nível de gerenciamento de resultado após a adoção mandatória de IFRS em uma amostra constituída por 353 empresas francesas. Os resultados de Leventis, Dimitropoulos e Anandarajan (2011) revelam que a adoção de IFRS na União Europeia aumentou a qualidade dos lucros mitigando a tendências de bancos comerciais gerenciarem resultado via reconhecimento de provisões.

Em relação ao reconhecimento tempestivo de perdas, espera-se que uma informação contábil com qualidade superior esteja associada com uma maior frequência no reconhecimento de perdas. A literatura sugere que uma característica de uma informação contábil com qualidade superior é que grandes perdas são reconhecidas à medida que ocorrem ao invés de serem diferidas para períodos futuros (LEUZ, NANDA e WYSOCKI, 2003; BALL e SHIVAKUMAR, 2005; 2006). Ball e Shivakumar (2005) encontraram que o reconhecimento tempestivo de perdas é menos predominante em empresas sem títulos negociados no mercado do que empresas com títulos negociados no Reino Unido. Eles interpretam esse resultado como uma consequência direta de uma menor demanda por alta qualidade da informação contábil para empresas fechadas. Christensen, Lee e Walker (2008) encontraram que a adoção voluntária de IFRS na Alemanha está associada com uma redução no gerenciamento de resultados e um reconhecimento mais tempestivo de perdas.

Nesse sentido, a predição é de que as empresas que pertençam ao grupo serious adopters tenham uma redução no gerenciamento de resultados, passem a ter value relevance dos valores contábeis e, também, um maior reconhecimento tempestivo das perdas em relação aos ganhos econômicos após a adoção de IFRS.

\subsection{CARACTERÍSTICAS INSTITUCIONAIS E SEU IMPACTO SOBRE A QUALIDADE DA INFORMAÇÃO CONTÁBIL}

Apesar do incremento de qualidade predito com a adoção de IFRS, é difícil afirmar que a simples adoção de um conjunto de normas seja condição suficiente para aumentar a qualidade da informação contábil (DYE e SUNDER, 2001). Por um lado, se normas e 
regulações uniformes são capazes de fornecer benefícios econômicos agregados, por outro lado os custos individuais e agregados de uma regulação uniforme para empresas, investidores e outros stakeholders dificilmente são reconhecidos ou até mesmo discutidos (LEUZ e WYSOCKI, 2008). Particularmente, o padrão IFRS baseia-se fortemente nas regulações de países e mercados que são voltados para o interesse dos investidores. Além disso, esses países desenvolvidos possuem um ambiente institucional que complementa o tipo de regulações que são desenvolvidas nesses mercados. Assim, dificilmente o padrão IFRS será superior ou efetivo em países onde há uma lacuna nas infraestruturas institucionais para dar suporte à sua efetiva aplicação e enforcement necessário de normas globais uniformes.

O ambiente legal e institucional de um país pode afetar os incentivos na divulgação das demonstrações financeiras e, assim, influenciar a qualidade da informação financeira divulgada aos investidores. Ball, Kothari e Robin (2000) analisam empresas de sete países que diferem em relação aos seus modelos de governança e o grau em que eles resolvem problemas de assimetria de informação via disclosure ou comunição privada. Eles mostram que empresas de países common law exibem maior reconhecimento tempestivo de perdas. Leuz, Nanda e Wysocki (2003) avaliaram o nível de gerenciamento de resultados e a falta de transparência dos lucros contábeis divulgados em 31 países. Eles mostram que tanto as leis de proteção ao investidor e o enforcement dessas leis são importantes em determinar a qualidade da informação divulgada. Mais importante, eles mostram que esses efeitos da proteção dos investidores persistem mesmo após controlar pelas regras contábeis desses países. Uma implicação desses estudos é de que normas e regulações contábeis mandatórias não podem ser consideradas de forma isolada e de que essas regras podem ter sua efetividade limitada se não forem levados em consideração outros fatores econômicos e institucionais que afetam os incentivos de divulgação das empresas.

Ball, Robin e Wu (2003) avaliam as propriedades de quatro países asiáticos que possuem normas contábeis similares a outros países common law (ou seja, Estados Unidos ou Grã-Bretanha), mas diferentes estruturas econômicas e institucionais. Eles encontram que os lucros das empresas de Hong Kong, Malásia, Singapura e Tailândia possuem propriedade similares a de países code law e são menos tempestivos do que 
aqueles divulgados por empresas norte americanas ou britânicas. Então, apesar da similaridade das normas contábeis, as características dos lucros divulgados dependem de fatores institucionais. Esses resultados mostram que outros fatores institucionais podem limitar a efetividades nas normas contábeis, levando a demonstrações financeiras com qualidade inferior.

Um dos fatores é a estrutura de propriedade da empresa, que responde à estrutura institucional do país (LA PORTA, LOPEZ-DE-SILANES e SHLEIFER, 1999). As pesquisas revelam que as estruturas de propriedade modelam os incentivos de divulgação e, portanto, a qualidade das demonstrações financeiras. Para uma amostra de empresas do Leste Asiático, Fan e Wong (2002) encontram uma relação negativa entre concentração acionária e o conteúdo informacional dos lucros, uma vez que a dispersão acionária limita o fluxo de informação privilegiada. Haw et al. (2004) encontram que o gerenciamento de resultado é significativamente limitado em países com forte proteção dos direitos dos acionistas minoritários (tendo como proxy a tradição legal do país e a eficiência do sistema jurídico) e instituições extralegais efetivas (tendo como proxy a efetividade das leis de concorrência econômica, difusão da imprensa e similaridade contábil-fiscal). Esses resultados enfatizam que mudanças isoladas na regulação e normas contábeis de disclosure podem levar a resultados inesperados ou não efetivos se outros arranjos institucionais, tais como estruturas de propriedade, forem ignorados.

Portanto, a visão dos fatores institucionais na divulgação contábil prediz que as estruturas institucionais do país e suas mudanças possuem um papel importante em explicar efeitos do mercado de capitais na adoção de IFRS. Tudo o mais constante, países com melhores mecanismos de enforcement e estruturas institucionais que forneçam fortes incentivos de divulgação possuem maior chance de exibir efeitos do mercado de capitais na adoção de IFRS.

O conjunto de evidências empíricas dessa seção fornece sustentação para o argumento de que o grupo de empresas com baixa qualidade da informação contábil e situada em um país com deficiências nos mecanismos de enforcement e nas estruturas institucionais possam não exibir uma melhora em termos de informação contábil. É predito que essas empresas tenham maior probabilidade de adotar o padrão IFRS meramente como um rótulo, ou seja, sem qualquer mudança significativa nas práticas de divulgação. 


\subsection{INCENTIVOS ECONÔMICOS NO NÍVEL DA EMPRESA}

Da seção anterior, concluiu-se que existe um conjunto de fatores que faz com que cada país seja diferente dos demais em termos de aumento da qualidade da informação com a adoção de IFRS. Por outro lado, Ball e Shivakumar (2005) encontraram que o reconhecimento tempestivo de perdas é menos predominante em empresas britânicas sem títulos negociados no mercado do que empresas britânicas com títulos negociados. Eles interpretam esse resultado como uma consequência direta de uma menor demanda por alta qualidade da informação contábil para empresas fechadas. Mais importante, eles concluíram que a demanda de mercado por informação de alta qualidade é o principal direcionador das propriedades das demonstrações contábeis. Isso sugere que as características das empresas também podem ser consideradas como um fator que influencia a qualidade contábil.

Uma linha de pesquisa verifica a interação entre incentivos econômicos e normas contábeis na determinação da qualidade da informação contábil. Ball (2001) argumenta que a convergência para normas internacionais de contabilidade dificilmente seria alcançada simplesmente pela harmonização de normas contábeis. O autor argumenta que normas contábeis uniformes foram desenvolvidas para satisfazer as necessidades de países common law (como Estados Unidos e Reino Unido), onde a divulgação de informação reduze a assimetria de informação entre gestores e usuários das demonstrações contábeis; em lugares onde a dispersão da informação privada prevalece, esse modelo dificilmente seria bem sucedido. Assim, apesar da harmonização contábil poder ser alcançada por forças de mercado, o autor argumenta que dificilmente ela ocorreria como consequência da adoção mandatória das normas contábeis.

A adoção de IFRS não leva necessariamente à maior qualidade da informação contábil, pelo menos não para aquelas empresas que não possuem incentivos para adotá-las. Utilizando uma amostra de empresas que adotaram IFRS de forma voluntária em 30 países, Daske et al. (2013) encontraram um aumento na liquidez e queda no custo de 
capital apenas para aquelas empresas com fortes incentivos de divulgar a informação contábil de forma transparente. Christensen, Lee e Walker (2008) encontram que a adoção voluntária de IFRS está associada com uma redução no gerenciamento de resultado e no reconhecimento mais tempestivo de perdas. Por outro lado, os autores não encontram nenhuma evidência de incremento de qualidade da informação contábil para empresas que adotaram IFRS após o período mandatório. Nesse sentido, a simples adoção do padrão IFRS pode não ser condição suficiente para reduzir o gerenciamento de resultado e aumentar o reconhecimento tempestivo de perdas.

Os resultados de Christensen, Lee e Walker (2008) permitem concluir que incrementos de qualidade verificados por empresas que adotaram o padrão IFRS voluntariamente poderiam ser direcionados pelos incentivos dessas empresas durante o período de adoção. Os autores identificaram que as empresas que adotaram IFRS somente no período mandatório possuíam características em comum, tais como: financiamento predominantemente bancário, menor demanda por informação do mercado de capitais e estrutura de propriedade mais concentrada. Os grandes fornecedores de capital dessas organizações frequentemente possuem acesso à informação interna e possuem um papel mais ativo na gestão da empresa. Esses fatores poderiam ser uma explicação do porque essas empresas possuem uma resistência em adotar o padrão IFRS e do porque elas não possuem fortes incentivos de reduzir o gerenciamento de resultados e aumentar o reconhecimento tempestivo de perdas após a adoção de IFRS.

Gaio (2010) encontra que o ambiente institucional do país não é o maior determinante da qualidade dos lucros das empresas e de que as características específicas das empresas possuem um poder explicativo incremental em relação às características do país. De forma similar, Isidro e Raonic (2012) encontram que incentivos específicos às empresas possuem um papel predominante em explicar a qualidade da informação contábil relativamente aos fatores no nível país. Os resultados de Lopes e Walker (2008) revelam que incentivos no nível das empresas impactam significativamente as características dos números contábeis após controlar pelas normas contábeis e pelo ambiente institucional. Grande parte das diferenças nas características dos números contábeis é direcionada por variáveis no nível da empresa e tais diferenças dificilmente são eliminadas pela imposição de normas e regras uniformes. De forma geral, esses 
estudos revelam que os incentivos econômicos para divulgação afetam fortemente a aplicação de facto das normas contábeis e, assim, diferenças nos incentivos, ceteris paribus, levam a diferenças na qualidade dos lucros.

O pressuposto de que as normas contábeis por si só não determinam a qualidade da informação contábil fornece sustentação para o argumento de que o grupo serious adopters irá presenciar um incremento de qualidade após a adoção do padrão IFRS.

Sem dúvida, isso não implica afirmar que as normas não importam, mas de que existem outras forças que moldam a qualidade das demonstrações contábeis e que as normas contábeis deveriam ser vistas como uma dessas forças. Nesse mesmo raciocínio, Ball et al. (2000) argumentam que a adoção de normas contábeis de alta qualidade como o padrão IFRS poderia ser vista como uma condição necessária, mas não suficiente para uma informação contábil com qualidade.

Nesse sentido, a hipótese deste trabalho é: existe heterogeneidade no ganho de qualidade informacional entre empresas com a adoção de IFRS. 


\section{DESENHO DA PESQUISA}

\subsection{VISÃO GERAL}

Para testar a hipótese foi usada uma amostra de empresas brasileiras durante o período de 2003 a 2014. Foi investigada a qualidade da informação contábil antes e após a adoção do padrão IFRS para três grupos de empresas com diferentes incentivos de divulgação da informação contábil e com diferentes níveis de qualidade da informação antes da adoção do padrão IFRS.

Os testes estão estruturados em dois três passos. No primeiro passo foi feita a separação das empresas listadas na BOVESPA em três grupos. As empresas foram agrupadas em termos de incentivos de divulgação dados pelo mercado acionário, bem como sua respectiva qualidade da informação contábil antes da adoção do padrão IFRS. Em seguida foram selecionadas e testadas medidas de qualidade informacional para cada um dos três grupos de empresas antes e após 2008. Foram testados value relevance, conservadorismo condicional e gerenciamento de resultados.

Por último, foram realizados dois testes de robustez. O primeiro teste procura verificar se os resultados para os grupos ADR e serious adopters se mantém, mesmo quando esses dois grupos são analisados de forma conjunta. Já o segundo teste de robustez procura investigar os impactos da desvinculação da contabilidade financeira da contabilidade tributária sobre os resultados dos testes de qualidade. Afinal de contas, possíveis ganhos de qualidade poderiam estar relacionados com o fim da vinculação da contabilidade tributária sobre a contabilidade financeira, relativizando os efeitos da adoção do padrão IFRS.

2.2 AGRUPAMENTO DE EMPRESAS COM DIFERENTES QUALIDADES DA INFORMAÇÃO CONTÁBIL ANTES DA ADOÇÃO DE IFRS 
O ambiente regulatório americano é considerado como um dos mais exigentes internacionalmente. Pownall e Schipper (1999), Ashbaugh e Olsson (2002) e Lang, Ready e Wilson (2006) sugerem que empresas não americanas exigidas a divulgar seus demonstrativos financeiros com base nas normas norte-americanas (U.S. GAAP) escolhem políticas ou práticas contábeis sob suas próprias normas nacionais que são mais próximas aos PCGA norte americanos.

A emissão de títulos no mercado norte americano está associado com uma maior qualidade da informação contábil. Ball (2001) conclui que ambientes regulatórios como o dos Estados Unidos focam no reconhecimento tempestivo de perdas (ao invés da suavização ao longo do tempo), que é consistente com um aumento na volatilidade dos lucros. Apesar de não existir a obrigação de mudar a divulgação em seu próprio país, Lang, Raedy e Yetman (2003) sugerem que as empresas que emitem ADR's apresentam mudanças que tornam os lucros mais voláteis e, portanto, com menor grau de suavização. Lang, Lins e Miller (2003) encontram que empresas sediadas em países codelaw e que possuem ADR's possuem 4,10 mais analistas do que empresas que não possuem ADR's, enquanto que esse número cai para 1,36 em países common law. Isso traz evidências do gap existente entre o monitoramento do mercado acionário em países codelaw, como o Brasil, e o mercado norte americano.

Assim, é predito que empresas que buscaram recursos externos via emissão de ações no mercado norte americano possuíam qualidade informacional superior mesmo antes da adoção de IFRS. Já as empresas listadas na BOVESPA, mas que não possuíam ADR's no ano de 2007 foram classificadas como de qualidade inferior. É predito que essas empresas não possuíam incentivos suficientes, antes da adoção do padrão IFRS, para divulgar uma informação de qualidade superior.

Para validar a variável ADR como proxy para qualidade superior testou-se value relevance e conservadorismo condicional para as empresas que possuíam títulos emitidos tanto na BOVESPA quanto na NYSE durante o período de 2003 a 2007. Se essas empresas possuíssem, de fato, qualidade superior, elas apresentariam conservadorismo condicional e value relevance dos números contábeis antes da adoção do padrão IFRS. 
Além disso, foi testado value relevance e conservadorismo condicional para a amostra de empresas listadas na BOVESPA, mas que não possuíam ADR's no ano de 2007. É predito que esse grupo não exibia value relevance e conservadorismo condicional antes de 2008.

Os resultados desses testes são apresentados nas tabelas 10 e 11 no subitem Resultados para os Testes de Qualidade da Informação Contábil.

\subsection{AGRUPAMENTO DE EMPRESAS COM INCENTIVOS ECONÔMICOS SIMILARES}

Daske et al (2013) utilizam variáveis de incentivo para separar as empresas que adotam IFRS de forma séria das empresas que adotam apenas como um rótulo. Os autores assumem que as empresas classificadas como serious adopters teriam melhoras em sua estratégia de divulgação com a adoção do IFRS. Por outro lado, o restante das empresas, label adopters, adotaria o padrão IFRS sem qualquer mudança significante de divulgação. Os gestores dessas últimas poderiam adotar o padrão IFRS por razões contratuais e, portanto, sem qualquer compromisso com maior transparência aos investidores.

Daske et al (2013) apontam que empresas maiores, com maior necessidade de obtenção de recursos, maiores oportunidades de crescimento e um menor nível de concentração acionária seriam classificadas como serious adopters e, assim, possuiriam incentivos em fornecer uma informação mais transparente. Os autores utilizam o logaritmo natural do valor de mercado (tamanho da empresa), a razão passivo/ativo (necessidade de obtenção de recursos), a razão market-to-book (oportunidade de crescimento) e a percentagem dos dois primeiros acionistas com direito a voto (concentração acionária) como proxies das variáveis que denotam incentivos para uma divulgação mais transparente. 
Beck et al. (2005) argumentam que empresas maiores conseguem absorver melhor os custos da divulgação, são mais sensíveis à visibilidade a fim de atrair capitais e, normalmente, são submetidas a exigências de divulgação mais elevadas por parte de acionistas múltiplos e institucionais e por stakeholders políticos e sociais. Santos, Ponte e Mapurunga (2014) encontram que o tamanho da empresa produz um impacto positivo significativo sobre os níveis de conformidade por parte das empresas brasileiras com a divulgação requerida pelo IFRS. Seguindo o trabalho de Daske et al (2013), a proxy de tamanho utilizada nesse trabalho é o logaritmo natural do valor de mercado.

Quanto maior a necessidade de financiamento, maior a propensão de a empresa adotar as práticas de convergência de maneira que melhore sua avaliação pelo financiador (Francis et al., 2008). Seguindo o trabalho de Daske et al (2013), a necessidade de financiamento é medida pela razão passivo/ativo.

Empresas com fortes oportunidades de crescimento estão propensas a precisar de financiamento externo para custear os projetos de investimento presentes e futuros. Estas companhias precisam de alguma forma, se comprometer voluntariamente a não expropriar seus investidores por meio da adoção de práticas contábeis mais rigorosas. Assim, quanto maior a necessidade de financiamento, maior a propensão de a empresa adotar as práticas de convergência de maneira que melhore sua avaliação pelo financiador (Francis et al., 2008). Seguindo o trabalho de Daske et al (2013), a oportunidade de crescimento da empresa é mensurada pelo índice market-to-book (MTB).

A concentração acionária é definida como a soma dos dois maiores acionistas com direito a voto. Anderson (1999) mostra que as empresas brasileiras possuem elevada concentração acionária e possuem baixa dependência do financiamento externo. Uma das consequências da estrutura de propriedade concentrada é de que o principal problema de governança das empresas brasileiras não é entre gestores e acionistas (problema de agência tipo I), mas entre o acionista controlador e os acionistas minoritários (problema de agência tipo II). É predito que quanto maior a concentração acionária, menor tenderia o monitoramento do mercado acionário e, portanto, uma menor demanda por demonstrações financeiras de maior qualidade. 
Esse trabalho utilizou as quatro variáveis e proxies utilizadas no trabalho de Daske et al (2013) e acrescentou as variáveis volume de negociação e alíquota efetiva de IR/CSSL para identificar as empresas com incentivos para melhorar a qualidade da informação contábil divulgada.

No que diz respeito à variável volume de negociação, a hipótese de seleção adversa assevera que quando um grupo de acionistas possui informação privilegiada, há um ambiente de assimetria de informação que reduz a liquidez (GROSSMAN e STIGLITZ, 1980; GLOSTEN e MILGROM, 1985; KYLE, 1985; EASLEY e O’HARA, 1987). É predito que quanto maior o volume de negociação, maior tenderia o incentivo dessa empresa em divulgar uma informação de maior qualidade.

A alíquota efetiva de IRPJ/CSSL é definida como a razão entre a despesa corrente de IRPJ/CSSL e o Lucro antes do IRPJ/CSSL (LAIR). Em mercados de capitais com elevada concentração acionária, como o Brasil, aquelas empresas com maior concentração acionária e, portanto com menor monitoramento do mercado possuem outros incentivos econômicos como, por exemplo, a minimização do pagamento de tributos. Scholes et al. (2002) argumentam que grandes acionistas que se mantêm próximos às empresas têm um incentivo a monitorar as atividades de economia tributária dos gestores e que essas firmas provavelmente escolhem oportunidades de economia de tributos envolvendo diferenças contábil-fiscais permanentes, mesmo se essas oportunidades reduzirem o lucro contábil. É predito que quanto menor o monitoramento do mercado acionário, menor tenderia a ser a alíquota efetiva de IRPJ/CSSL.

Pressupõe-se que o grupo de empresas com menor qualidade informacional antes de 2008 passou a ser dividido em dois subgrupos após a adoção de IFRS: empresas que continuaram com uma vinculação contábil-fiscal (label adopters) e um segundo grupo que passou a ter uma maior qualidade da informação contábil (serious adopters).

Para separar essas empresas, foi utilizada a técnica estatística de análise de cluster. Essa técnica de agrupamento tem por objetivo principal definir a estrutura dos dados de maneira a alocar as observações mais parecidas no mesmo grupo. Ela procura 
maximizar a homogeneidade dos objetos dentro dos grupos e maximizar a heterogeneidade entre os demais grupos (FÁVERO et al. 2009).

As informações das variáveis de incentivos econômicos são relativas ao ano de 2007 uma vez que, se existissem incentivos econômicos para a empresa divulgar informações de maior qualidade para investidores, esses incentivos já deveriam existir em 2007.

É predito as empresas do grupo serious adopters são relativamente maiores, possuem um volume de negociação maior, possuem uma alíquota efetiva de IR-CS relativamente maior, possuem maiores oportunidades de crescimento, possuem maiores necessidades de financiamento, mas em contrapartida, possuem uma concentração acionária menor.

\subsection{MEDIDAS DE QUALIDADE DA INFORMAÇÃO CONTÁBIL}

Não existe uma medida de QIC universalmente aceita (Dechow, Ge e Schrand, 2010), então, qualquer proxy isoladamente não consegue cobrir todas as facetas da qualidade dos lucros. Para mitigar esse problema, decidiu-se utilizar a "abordagem de portfólio" proposta por Barth et al. (2008). Essa abordagem define o conteúdo informacional contábil como um padrão de evidências fornecidas por diversas medidas. O uso de múltiplas medidas mitiga a possibilidade de que os resultados capturem outros fatores que não a qualidade da informação contábil, e de que esses outros fatores estejam direcionando os resultados.

\subsubsection{Teste de Conservadorismo Condicional}

O reconhecimento tempestivo de perdas econômicas geralmente aumenta a relevância das demonstrações financeiras (BALL; SHIVAKUMAR, 2005). Consistente com investidores demandando conservadorismo, LaFond e Roychowdhury (2008) utilizam a participação dos gestores nas ações da empresa como uma medida de 
separação entre propriedade e controle que leva a problemas de agência entre gestores e investidores. Eles predizem e encontram que o conservadorismo é maior quando a participação dos gestores é menor.

As pesquisas de Ball (2001) e Watts (2003) sugerem que investidores demandam conservadorismo na contabilidade em função dele mitigar problemas de agência de duas maneiras. Em primeiro lugar, o conservadorismo disciplina as decisões de investimento dos gestores (BALL, 2001). Ao reconhecer as perdas econômicas de projetos não viáveis de uma maneira tempestiva, a contabilidade conservadora envia um sinal aos investidores para analisar essas perdas. Isso pode prejudicar a reputação dos gestores e ameaçar a sua permanência no emprego. Em segundo lugar, o conservadorismo reduz o incentivo e capacidade dos gestores superavaliarem os lucros (WATTS, 2003). À medida que a compensação dos gestores está atrelada aos lucros, o conservadorismo penaliza os gestores pelos resultados negativos (perdas econômicas) de uma maneira tempestiva, porém adia recompensas de resultados positivos até que esses sejam realizados, reduzindo, dessa forma, o incentivo e a capacidade de superestimar o valor criado. Dessa forma, o reconhecimento tempestivo das perdas econômicas é um atributo importante da qualidade das demonstrações financeiras.

Para testar o conservadorismo condicional utilizou-se o Modelo Reverso de Lucros Associados a Retornos de Basu (1997).

\subsubsection{Modelo Reverso de Lucros Associados a Retornos}

O modelo de conservadorismo condicional parte da premissa de que, no momento do reconhecimento de uma futura perda econômica contida no lucro de uma determinada entidade, o mercado de capitais reconheceria essa perda oportunamente no retorno das ações (BRITO, 2010).

Os preços das ações no mercado derivam da expectativa dos investidores em relação ao desempenho futuro da empresa considerando o conjunto de informações disponíveis em determinado momento. As alterações nos preços indicam o surgimento de novas 
informações que afetam o desempenho futuro da empresa. Retornos positivos revelam uma expectativa de melhor desempenho (boas notícias) e retornos negativos evidenciam uma expectativa de pior desempenho (más notícias) (BRITO, 2010).

Na hipótese de conservadorismo, o lucro terá relação mais forte com os retornos negativos do que com os retornos positivos, uma vez que a contabilidade anteciparia o registro das perdas econômicas já incorporadas aos preços das ações. Portanto, o lucro reflete mais rapidamente as perdas econômicas (más notícias) do que os ganhos econômicos (boas notícias).

O modelo é dado pela regressão reversa entre lucros e retornos:

$$
E A R N_{i t}=\alpha+\beta_{1} \mathrm{DR}_{\mathrm{it}}+\beta_{2} \operatorname{Ret}_{\mathrm{it}}+\beta_{3} \mathrm{DR}_{\mathrm{it}} * \operatorname{Ret}_{\mathrm{it}}+\varepsilon_{\mathrm{jt}}
$$

Equação 1

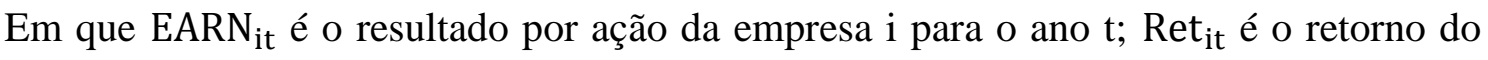
preço da ação para a empresa i no ano t; e $\mathrm{DR}_{\mathrm{it}}$ é uma dummy que assume 1 quando o retorno da ação é negativo e 0 caso contrário.

O coeficiente $\beta_{2}$ mede a resposta dos lucros aos retornos quando esses são positivos, enquanto $\left(\beta_{2}+\beta_{3}\right)$ mede a resposta dos lucros aos retornos quando esses são negativos. $\mathrm{O}$ coeficiente $\beta_{3}$ mede a resposta incremental dos lucros aos retornos negativos relativamente aos retornos positivos. O tamanho relativo dos coeficientes dos retornos negativos sobre os coeficientes dos retornos positivos é dado por $\left(\beta_{2}+\beta_{3}\right) / \beta_{2}$ (SILVA, 2013).

Sob a hipótese de conservadorismo, os lucros serão mais fortemente relacionados com os retornos negativos do que com os retornos positivos, o que implica $\beta_{2}+\beta_{3}>\beta_{2}$, isto é, $\beta_{3}>0$. Dessa forma, o coeficiente $\beta_{3}$ é uma medida do reconhecimento oportuno e assimétrico das perdas em relação aos ganhos nos lucros contábeis. Um coeficiente $\beta_{3}$ positivo e significante revela a presença de conservadorismo condicional (SILVA, 2013).

Na tabela 1 é apresentada a composição da amostra para o Modelo Reverso de Lucros Associados a Retornos durante o período de 2003 a 2007 e na tabela 2 é apresentada a composição da amostra para esse teste durante o período de 2008 a 2014. Os missing 
values dizem respeito às observações com ausência de dados para qualquer uma das variáveis do modelo. Além disso, foram excluídas as observações classificadas como outliers, definidas como aquelas observações acima ou abaixo de três desvios-padrão em relação à média padronizada da variável de interesse (FÁVERO et al, 2009).

Tabela 1 - Amostra para o Modelo Reverso de Lucros Associados a Retornos (2003 a 2007)

\begin{tabular}{lccc}
\hline & ADR & Serious Adopters & Label Adopters \\
\hline Total de observações da amostra no período & 638 & 820 & 11561 \\
$2003-2007$ & & & \\
Menos & 166 & 337 & 8418 \\
(-) Missing Values & 13 & 16 & 231 \\
(-) Outliers & & & 2912 \\
Amostra para o modelo & 459 & 467 & 2 \\
Reverso de Lucros Associados a Retornos & & & \\
\hline
\end{tabular}

Fonte: Elaboração Própria

$A D R=$ grupo de empresas com ADR's antes de 2008;

Serious Adopters = subgrupo de empresas com maior monitoramento do mercado acionário;

Label Adopters = subgrupo de empresas com menor monitoramento do mercado acionário;

Tabela 2 - Amostra para o Modelo Reverso de Lucros Associados a Retornos (2008 a 2014)

\begin{tabular}{lccc}
\hline & ADR & Serious Adopters & Label Adopters \\
\hline Total de observações da amostra no período & 831 & 1067 & 15028 \\
$2008-2014$ & & & \\
Menos & 142 & 135 & 9476 \\
(-) Missing Values & 17 & 21 & 301 \\
(-) Outliers & & & 5251 \\
Amostra para o modelo & 672 & 911 & 5 \\
Reverso de Lucros Associados a Retornos & & & \\
\hline
\end{tabular}

Fonte: Elaboração Própria

$A D R=$ grupo de empresas com ADR's antes de 2008;

Serious Adopters = subgrupo de empresas com maior monitoramento do mercado acionário;

Label Adopters = subgrupo de empresas com menor monitoramento do mercado acionário;

Os modelos de regressão são estimados com base na equação 1 usando o método de mínimos quadrados ordinários. Os resultados são apresentados nas Tabelas 10 e 12. 


\subsubsection{Teste de Gerenciamento de Resultados}

A contabilidade tem como objetivo fornecer informações para seus usuários apoiarem suas decisões (ANGELO, 1986). Sendo assim, é importante que as informações disponibilizadas pelas empresas possuam alto grau de qualidade e, por consequência, sejam confiáveis para que os investidores possam ter melhores condições de alocar eficientemente os seus recursos (HOLTHAUSEN; WATTS, 2001).

Logo, pode-se afirmar que existe uma baixa qualidade nas informações contábeis nos seguintes casos: quando são manipuladas; quando existe um número excessivo de itens não recorrentes; e na falta de transparência no processo de evidenciação, mesmo quando as escolhas contábeis tenham sido realizadas em concordância com as normas contábeis vigentes (PAULO, 2007).

O gerenciamento de resultados é uma ferramenta utilizada pelos administradores para que as informações contábeis possuam um conteúdo mais otimista do que o esperado pelos investidores. Dessa forma, o GR (gerenciamento de resultados) é uma intervenção intencional nos relatórios financeiros externos, com a intenção de que os relatórios não representem a realidade intrínseca ao negócio (GIOIELLI; CARVALHO; SAMPAIO, 2013).

Quando utilizado, faz com que as informações contábeis percam sua qualidade, pois passa ideias equivocadas sobre a real situação da empresa, deixando de ser um instrumento confiável de informação. Assim, embora o gerenciamento de resultados não seja ilegal, ele pode distorcer o conteúdo informativo das demonstrações financeiras de forma a prejudicar os acionistas.

2.4.2.1 Modelo de Accruals Discrionários de Kothari, Leone e Wasley (2005) 
Conforme Healy (1985) o gerenciamento de resultados, por meio de manipulação de resultados contábeis, pode ser efetuado por meio de apropriações contábeis ou de mudanças de políticas contábeis.

Apesar das acumulações positivas sugerirem que os resultados reportados sejam maiores do que o fluxo de caixa gerado pelas operações da empresa, as acumulações positivas, por si só, não são uma evidência de GR. Nas operações cotidianas das empresas, alguns registros com a natureza de acumulações são consistentes com o regime contábil de competência (accrual basis), e às vezes são apropriados e necessários para prover uma boa apresentação dos resultados. A manipulação acontece quando os administradores, de forma discricionária, aumentam ou diminuem as acumulações com qualquer propósito específico que não seja expressar a real situação econômico-financeira do negócio. Portanto, faz-se necessário decompor as acumulações em duas parcelas: as acumulações não-discricionárias (normais), que são oriundas das atividades da empresa, e as acumulações discricionárias, que são artificiais e têm a intenção apenas de manipular os resultados contábeis (GIOIELLI; CARVALHO; SAMPAIO, 2013).

Diversas metodologias têm sido desenvolvidas para fazer tal decomposição, por exemplo, Healy (1985), Angelo (1986), Jones (1991), Dechow et al. (1995), Kang e Sivaramakrishnan (1995) e Kothari et al. (2005). Esses procedimentos são similares a um estudo de evento: cria-se um grupo de controle e suas características operacionais e financeiras são utilizadas para estimar as acumulações normais (não-discricionárias) para o grupo tratado. Depois, as acumulações anormais (GR) são estimadas como a diferença entre as acumulações observadas e as acumulações não-discricionárias (GIOIELLI; GLEDSON DE CARVALHO; SAMPAIO, 2013).

Para Martinez (2013), os modelos de accruals discricionários, embora falhos, constituem um mecanismo pragmático para poder segregar comparativamente empresas que gerenciam resultados mais e menos. Pela métrica, todas as empresas num determinado momento gerenciariam, entretanto isso é falho, ou mesmo irrelevante. Segundo o autor, o mais importante é focalizar na comparação e verificar quais firmas que pela métrica gerenciam mais ou menos. Na análise comparativa, as proxies de accruals discricionários podem oferecer importantes informações para avaliar 
circunstâncias e contingências nas quais podemos confiar mais ou menos nos resultados contábeis divulgados.

No Brasil, o Modelo Jones Modificado e do Modelo KS são os mais populares para detectar o gerenciamento de resultados por accruals. Alguns trabalhos inclusive aplicam as duas metodologias. Como possíveis tendências, para aprimoramento dos modelos, destaque-se Kothari, Leone e Wasley (2005) que propôs um modelo ajustado sobre aquele tradicional de Jones, sugerindo uma análise confrontada com o desempenho, controlando o cálculo dos accruals discricionários com firmas dentro de um mesmo grupo e confrontada com o desempenho (MARTINEZ, 2013).

Nesse sentido, Grecco (2013) avalia quais dos modelos de accruals discricionários apresentam melhores propriedades estatísticas e, portanto, qual seria mais adequado. Dentre os critérios utilizados, a autora utiliza o critério de informação de Akaike; critério de informação de Schwarz; critério de informação Hannan-Quinn; $\mathrm{R}^{2}$ ajustado; e p-value global do modelo. Ela conclui que o Modelo Jones modificado por Kothari, Leone e Wasley (2005) polinomial omitindo-se a variação de contas a receber apresenta os melhores critérios de informação dentre as variações estudadas destes modelos.

Kothari, Leone e Wasley (2005), a partir das observações de Dechow, Sloan e Sweeney (1995), ressaltaram que o Modelo Jones Modificado proposto era suscetível a apresentar acréscimos das apropriações discricionárias quando a empresa estivesse em crescimento (GRECCO, 2013). Desta forma, apresentam outro modelo, que é uma nova modificação do Modelo Jones, incluindo o ROA (retorno dos ativos):

$$
\frac{A T_{i t}}{A_{i t-1}}=\alpha\left(\frac{1}{A_{i t-1}}\right)+\beta_{1}\left[\left(\frac{\Delta R E C_{i t}-\Delta C R_{i t}}{A_{i t-1}}\right)\right]+\beta_{2}\left(\frac{P P E_{i t}}{A_{i t-1}}\right)+\beta_{3} R O A_{i t}+\varepsilon_{i t}
$$

Equação 2

Em que $A T_{i t}$ representa o total de accruals para a empresa i no período t; $A_{i t-1}$ representa o total de ativos para a empresa $\mathrm{i}$ no período $\mathrm{t}-1 ; \Delta R E C_{i t}$ representa a variação de receita de vendas da empresa i do período t-1 para o período $\mathrm{t} ; \Delta C R_{i t}$ representa a variação de contas a receber da empresa i do período t-1 para o período t; $P P E_{i t}$ representa o valor do imobilizado da empresa i no período t; e $R O A_{i t}$ representa o retorno sobre os ativos da empresa i no período t. 
Como os dados para o cálculo dos accruals são disponibilizados somente a partir de 2005, não foram utilizados os anos de 2003 e 2004 para o modelo de gerenciamento de resultados.

Para investigar o grau de gerenciamento de resultados das empresas após a adoção do padrão IFRS, utilizou-se a seguinte equação (TENDELOO; VANSTRAELEN, 2005; SILVA, 2013):

$$
|A D|_{i t}=\alpha+\beta_{1} I F R S_{i t}+\varepsilon_{i t}
$$

Equação 3

Em que $|A D|_{i t}$ representa os accruals discricionários da empresa i no período $\mathrm{t}$; $\mathrm{e}$ $I F R S_{i t}$ é uma dummy que assume o valor de 1 para os anos após a adoção das normas internacionais e 0 caso contrário. Se determinada empresa diminui o grau de gerenciamento de resultados após a adoção de IFRS, espera-se que o coeficiente $\beta_{1}$ seja negativo e estatisticamente significante.

Nesse sentido, é predito que apenas o grupo serious adopters irá presenciar uma redução significante do nível de gerenciamento de resultados. Afinal de contas, se essas empresas desejam que os investidores financiem suas operações, elas devem preparar demonstrações financeiras com representação fidedigna da realidade da entidade.

Para o grupo $A D R$, não se espera mudança significativa do gerenciamento de resultados após a adoção do padrão IFRS, pois se argumenta que esse grupo já havia perseguindo um nível de gerenciamento de resultados relativamente menor quando comparado com as demais empresas.

Por fim, para o grupo label adopters das demonstrações financeiras, também, não se espera uma redução do gerenciamento de resultados. Argumenta-se que esse grupo de empresas possui baixos incentivos econômicos para divulgar uma informação de maior qualidade e, assim, tem poucos incentivos em não gerenciar resultados.

Na tabela 3 é apresentada a composição da amostra para o Modelo de Kothari, Leone e Wasley (2005) durante o período de 2003 a 2007 e na tabela 4 é apresentada a composição da amostra para esse teste durante o período de 2008 a 2014. Os missing values dizem respeito às observações com ausência de dados para qualquer uma das 
variáveis do modelo. Além disso, foram excluídas as observações classificadas como outliers, definidas como aquelas observações acima ou abaixo de três desvios-padrão em relação à média padronizada da variável de interesse (FÁ́VERO et al, 2009).

Tabela 3 - Amostra para o modelo de Accruals Discricionários de Kothari, Leone e Wasley (2005) de 2005 a 2007

\begin{tabular}{lccc}
\hline & ADR & Serious Adopters & Label Adopters \\
\hline Total de observações da amostra no período & 385 & 493 & 6359 \\
$2005-2007$ & & & \\
Menos & 141 & 301 & 5818 \\
(-) Missing Values & 8 & 10 & 127 \\
(-) Outliers & & & 414 \\
Amostra para o modelo & 236 & 182 & 4 \\
Accruals Discricionários de Kothari, Leone e Wasley & & & \\
\hline
\end{tabular}

Fonte: Elaboração Própria

$A D R=$ grupo de empresas com ADR's antes de 2008;

Serious Adopters = subgrupo de empresas com maior monitoramento do mercado acionário;

Label Adopters = subgrupo de empresas com menor monitoramento do mercado acionário;

Tabela 4 - Amostra para o modelo de Accruals Discricionários de Kothari, Leone e Wasley (2005) de 2008 a 2014

\begin{tabular}{lccc}
\hline & ADR & Serious Adopters & Label Adopters \\
\hline Total de observações da amostra no período & 831 & 1067 & 14450 \\
$2008-2014$ & & & \\
Menos & 191 & 217 & 9367 \\
(-) Missing Values & 17 & 21 & 289 \\
(-) Outliers & & & \\
Amostra para o modelo & 623 & 829 & 4794 \\
Accruals Discricionários de Kothari, Leone e Wasley & & & \\
\hline
\end{tabular}

Fonte: Elaboração Própria

$A D R=$ grupo de empresas com ADR's antes de 2008;

Serious Adopters = subgrupo de empresas com maior monitoramento do mercado acionário;

Label Adopters = subgrupo de empresas com menor monitoramento do mercado acionário;

Os modelos de regressão são estimados com base na equação 3 usando o método de mínimos quadrados ordinários. Os resultados são apresentados nas Tabelas 13, 14 e 15. 


\subsubsection{Modelo de Value Relevance}

De acordo com Barth, Beaver e Landsman (2001) o conteúdo informacional da contabilidade pode ser avaliado por meio de estudos de value-relevance, cujo objetivo é analisar a relevância da informação contábil para os investidores. Os testes de value relevance buscam aferir se um valor contábil será capaz de apresentar uma relação significativa com os preços de um mercado. Em caso positivo, tal valor seria considerado relevante pelo investidor para avaliar o desempenho econômico-financeiro de uma entidade e seria refletido nos preços de mercado (SUZART, 2013; SILVA; 2013).

Francis e Schipper (1999) argumentam que a relevância estaria relacionada à capacidade da informação contábil em afetar as decisões dos usuários da informação. Isso ocorreria quando a contabilidade fornecesse uma informação nova capaz de alterar a expectativa de desempenho futuro da empresa, fazendo com que os investidores revisem suas expectativas quanto à compra e venda das ações e, consequentemente, a precificação da empresa. Assim, em função da capacidade de transmitir informação, as variações apresentadas pelo lucro líquido seriam refletidas nos preços das ações por meio das decisões do usuário da informação contábil (SANTOS, 2012).

Nesse sentido, demonstrações de boa qualidade seriam aquelas em que o valor do lucro líquido e do patrimônio líquido apresentasse alto grau de associação com o preço das ações, indicando que os números contábeis são capazes de capturar a realidade econômica da empresa (SANTOS, 2012).

\subsubsection{Especificação do Modelo de Retorno}

A especificação do modelo de retorno ou Coeficiente de Resposta aos Lucros (ERC) considerada nesse trabalho é similar à adotada nos estudos de Easton e Harris (1991), Francis e Schipper (1999) e Nakao (2012):

$$
\operatorname{RET}_{i t+1}=\alpha+\beta_{1} L A I R_{i t}+\varepsilon_{i t}
$$

Equação 4 
Em que $R E T_{i t}$ é o retorno da ação i três meses após a data de encerramento das demonstrações contábeis; e $L A I R_{i t}$ é o valor do lucro antes do imposto de renda, dividido pelo total de ativos. Seguindo Nakao (2012), utilizou-se o lucro antes do imposto de renda ao invés do lucro líquido como uma maneira de considerar a informação que é orientada a investidores independentemente dos aspectos tributários, por exemplo, incentivos fiscais, presentes na despesa de imposto de renda e consequentemente no lucro líquido (HANLON, 2005).

O coeficiente $\beta_{1}$ corresponde ao Coeficiente de Resposta aos Lucros, em que o termo "resposta" não implica em causalidade, mas possui um sentido genérico para medir o grau de movimento conjunto entre o retorno das ações e uma série de lucros, não necessariamente implicando em uma relação de causalidade (PIMENTEL, 2009).

Na tabela 5 é apresentada a composição da amostra para o teste de Coeficiente de Resposta aos Lucros durante o período de 2003 a 2007 e na tabela 6 é apresentada a composição da amostra para esse teste durante o período de 2008 a 2014. Os missing values dizem respeito às observações com ausência de dados para qualquer uma das variáveis do modelo. Além disso, foram excluídas as observações classificadas como outliers, definidas como aquelas observações acima ou abaixo de três desvios-padrão em relação à média padronizada da variável de interesse (FÁVERO et al, 2009).

Tabela 5 - Amostra para o modelo de Value Relevance para o Modelo de Retorno (2003 a 2007)

\begin{tabular}{lccc}
\hline & ADR & Serious Adopters & Label Adopters \\
\hline Total de observações da amostra no período & 638 & 820 & 11561 \\
$2003-2007$ & & & \\
Menos & 92 & 323 & 8339 \\
(-) Missing Values & 13 & 16 & 231 \\
(-) Outliers & & & \\
Amostra para o modelo & 533 & 481 & 2991 \\
Value Relevance para o Modelo de Retorno & &
\end{tabular}

Fonte: Elaboração Própria $A D R=$ grupo de empresas com ADR's antes de 2008;

Serious Adopters = subgrupo de empresas com maior monitoramento do mercado acionário;

Label Adopters = subgrupo de empresas com menor monitoramento do mercado acionário; 
Tabela 6 - Amostra para o modelo de Value Relevance para o Modelo de Retorno (2008 a 2014)

\begin{tabular}{lccc}
\hline & ADR & Serious Adopters & Label Adopters \\
\hline Total de observações da amostra no período & 831 & 1067 & 15028 \\
$2008-2014$ & & & \\
Menos & 135 & 139 & 9466 \\
(-) Missing Values & 17 & 21 & 301 \\
(-) Outliers & & & 5261 \\
Amostra para o modelo & 679 & 907 & 5 \\
Value Relevance para o Modelo de Retorno & & & \\
\hline
\end{tabular}

Fonte: Elaboração Própria

$A D R=$ grupo de empresas com ADR's antes de 2008;

Serious Adopters = subgrupo de empresas com maior monitoramento do mercado acionário;

Label Adopters = subgrupo de empresas com menor monitoramento do mercado acionário;

Os modelos de regressão são estimados com base na equação 4 usando o método de mínimos quadrados ordinários. Os resultados são apresentados na Tabela 11 e 16. 


\section{RESULTADOS E DISCUSSÃO}

\subsection{ANÁLISE DE CONGLOMERADOS}

Em primeiro lugar, foi realizada uma correlação entre as variáveis que denotam maior ou menor monitoramento do mercado acionário. Em seguida, foi conduzida uma análise de conglomerados das empresas listadas na BOVESPA não classificadas no grupo $A D R$.

\subsubsection{Tabela de Correlação}

As correlações entre as variáveis que manifestam os incentivos econômicos possuem os sinais preditos na seção anterior (tabela 7). Mais especificamente, todas as variáveis foram negativamente correlacionadas com a variável concentração acionária. Por exemplo, o volume de negociação guarda uma relação negativa e estatisticamente significante com o grau de concentração acionária $(-0,511 * * *)$.

Tabela 7 - Tabela de correlação entre as variáveis de agrupamento

\begin{tabular}{lcccccc}
\hline & Valor Merc. & Passivo/Ativo & MTB & Vol. Neg. & Conc. Acion. & ETR \\
\hline Valor Merc. & 1,000 & & & & & \\
Passivo/Ativo & 0,041 & 1,000 & & & & \\
MTB & $-0,289$ & $-0,005$ & 1,000 & & & \\
Vol. Neg. & $0,622^{* * *}$ & 0,104 & $-0,229$ & 1,000 & & \\
Conc. Acion. & $-0,132 * *$ & $-0,143$ & $-0,082 * *$ & $-0,511 * * *$ & 1,000 & \\
ETR & 0,144 & 0,091 & $0,139 * *$ & 0,087 & $-0,152$ & 1,000 \\
\hline
\end{tabular}

Fonte: Elaboração Própria.

Asteriscos *, ** e *** denotam significância estatística bicaudal a 10\%, 5\% e $1 \%$ respectivamente.

Definições: Valor Merc. é definido como o logaritmo natural da média do valor de mercado da empresa no ano de 2007; Passivo/Ativo é definido como a razão entre o passivo total e o ativo da empresa no ano de 2007; MTB é a razão market-to-book da empresa no ano de 2007; Vol. Neg. é o logaritmo natural da média do volume de negociação da empresa no ano de 2007; Conc. Acion. é definida como a soma dos dois maiores acionistas com direito a voto; ETR é definida como a razão entre a despesa corrente de IRPJ/CSSL e o Lucro antes do IRPJ/CSSL (LAIR); 
Os resultados encontrados corroboram com resultados de outros estudos. Por exemplo, Rubin (2007) encontra que o grau de concentração acionária é negativamente relacionado com o grau de liquidez das empresas listadas na Bolsa de Valores de Nova York.

A relação negativa entre valor de mercado e concentração acionária é consiste com os argumentos de Demsetz e Lehn (1985), de quanto maior a empresa, ceteris paribus, maior é o valor de mercado de uma dada fração da empresa. O maior preço de uma dada fração da empresa deveria, por si só, reduzir o grau de concentração acionária. Além disso, é exigida uma menor parcela da empresa, para um mesmo nível de controle, quanto maior fosse a empresa.

Além disso, a relação negativa entre concentração acionária e alíquota efetiva de IR também tem respaldo na literatura. Scholes, Wolfson, Erickson, Maydew e Shevlin (2002) argumentam que grandes acionistas que se mantêm próximos às empresas têm um incentivo a monitorar as atividades de economia tributária dos gestores e que essas firmas provavelmente escolhem oportunidades de economia de tributos envolvendo diferenças contábil-fiscais permanentes, mesmo se essas oportunidades reduzirem o lucro contábil. Zeng (2011) verificou que empresas chinesas com concentração acionária apresentam menores alíquotas efetivas de imposto de renda.

Utilizando uma amostra de 148 companhias listadas na Bolsa Valores de São Paulo e por meio do Índice de Observância às Práticas de Convergência, Lima (2011) encontrou que empresas maiores, com maiores oportunidades de crescimento e estrutura de propriedade mais difusa estão mais propensas a adotarem as práticas de convergência de maneira que perfaçam mudanças materiais em suas políticas contábeis.

\subsubsection{Análise de Cluster}

Como argumentando anteriormente, as empresas listadas na BOVESPA foram separadas em dois grupos, a saber: empresas que emitiram ADR até o ano de 2008 e 
empresas que não emitiram ADR. O próximo passo foi separar as empresas que não emitiram ADR até o ano de 2008 em dois subgrupos por meio de uma análise de conglomerados.

Após a identificação de dois subgrupos de empresas pelo resultado da análise de conglomerados, calculou-se a média de cada variável para cada um dos subgrupos (tabela 8).

Ao aplicar o teste de comparação de médias, encontrou-se que as variáveis "valor de mercado", "volume de negociação", "concentração acionária" e "alíquota efetiva de IRRJ-CSSL” possuem médias estatisticamente diferentes entre os dois subgrupos.

Tabela 8 - Média das variáveis para cada subgrupo

\begin{tabular}{lcccccc}
\hline & Valor Merc. & Passivo/Ativo & MTB & Vol.Neg. & Conc.Acion. & ETR \\
\hline Média subgrupo A & $14,39^{*}$ & $55,66 \%$ & 0,66 & $8,84 * * *$ & $33,69 \% * * *$ & $34,5 \% * * *$ \\
Média subgrupo B & $13,84 *$ & $53,61 \%$ & 0,65 & $7,26 * * *$ & $80,41 \% * * *$ & $18,6 \% * * *$ \\
\hline
\end{tabular}

Fonte: Elaboração Própria.

Asteriscos *,** e *** denotam significância estatística bicaudal a 10\%, 5\% e 1\% respectivamente.

Definições: Valor Merc. é definido como o logaritmo natural da média do valor de mercado da empresa no ano de 2007; Passivo/Ativo é definido como a razão entre o passivo total e o ativo da empresa no ano de 2007; MTB é a razão market-to-book da empresa no ano de 2007; Vol.Neg. é o logaritmo natural da média do volume de negociação da empresa no ano de 2007; Conc.Acion. é definida como a soma dos dois maiores acionistas com direito a voto; ETR é definida como a razão entre a despesa corrente de IRPJ/CSSL e o Lucro antes do IRPJ/CSSL (LAIR);

Como argumentado na seção anterior, as variáveis da tabela 8 sinalizam um maior ou menor monitoramento do mercado acionário sobre a empresa. Um maior monitoramento está associado com uma maior demanda por informação contábil de qualidade, cujo objetivo, em última instância, é auxiliar na tomada de decisões. Em outras palavras, em fornecer informação capaz de alterar as crenças do usuário, bem como representar de forma fidedigna a situação econômica da empresa. Como o padrão IFRS é mais orientado ao mercado de capitais e mais abrangente em relação a grande parte dos PCGA nacionais, a empresa com maior monitoramento do mercado teria incentivo em aumentar a qualidade da informação contábil após a adoção do IFRS para sinalizar comprometimento e transparência para o mercado. 
Visto de outra forma, as empresas com baixo monitoramento do mercado acionário poderiam estar preocupadas, por exemplo, com a economia de tributos, sem conduzir a mudanças substanciais na divulgação da informação contábil. Se a informação financeira divulgada está de fato destacada da contabilidade para fins tributários, ela deve se apresentar útil para a tomada de decisões, com significativo value relevance. Do mesmo modo, a informação tem caráter mais tempestivo e deve apresentar conservadorismo condicional aos eventos econômicos. Não se espera que essas características estejam presentes na informação contábil fortemente influenciada pelos aspectos tributários, já que a contabilidade tributária não está voltada para a tomada de decisões.

Além disso, as novas normas podem ter imposto mudanças obrigatórias, mas a flexibilidade das IFRS oferece aos gestores algum nível discricionário; eles também podem simplesmente escolher não estar em conformidade com as normas. Em um exame de 279 empresas que fazem referência à aplicação das International Accounting Standards (IAS) in suas demonstrações de 1998, Street e Gray (2002) verificam que, em muitos casos, as políticas contábeis evidenciadas são inconsistentes com as IAS.

De maneira semelhante à Daske et al (2013), procura-se separar as empresas em serious adopters e label adopters. As primeiras possuem incentivos econômicos em divulgar uma informação contábil de maior qualidade ao passo que o segundo grupo teria outros incentivos que não em fornecer informação contábil de qualidade superior.

Tendo em vista as características do subgrupo B - elevada concentração acionária, baixa alíquota efetiva de IRPJ/CSSL e menor volume de negociação - assume-se que essas empresas não estariam engajadas em fornecer informação contábil de maior qualidade mesmo após a adoção do padrão IFRS. A baixa alíquota efetiva de IR seria um indicativo de ênfase na utilização de diferenças permanentes para economizar no pagamento de tributos. Seguindo a nomenclatura de Daske et al (2013), esse grupo foi denominado label adopters. É enfatizado o fato de utilizar apenas a nomenclatura de Daske et al (2013), afinal de contas, esse trabalho utilizou um método diferente para o agrupamento das empresas. 
Em contrapartida, as características do subgrupo A - relativa baixa concentração acionária, alíquota efetiva de IRPJ/CSSL próxima a 34\% e maior volume de negociação relativo ao subgrupo A - indicam que essas empresas possuem incentivos econômicos fortemente atrelados em fornecer informação relevante para o mercado que as monitora. Essas são, portanto, as empresas em que se espera um incremento de qualidade após a adoção do padrão IFRS e seriam chamadas de serious adopters. É enfatizado, novamente, o fato de utilizar apenas a nomenclatura de Daske et al (2013), pois esse trabalho utilizou um método diferente para o agrupamento das empresas.

\subsubsection{Estatística descritiva das variáveis de agrupamento}

A tabela 9 apresenta a estatística descritiva das variáveis que capturam um maior ou menor monitoramento do mercado acionário para os grupos serious adopters e label adopters. 
Tabela 9 - Estatística descritiva das variáveis de agrupamentos para os grupos serious adopters e label adopters

Painel A - Estatística descritiva para o grupo serious adopters

\begin{tabular}{lcccccc}
\hline & Valor Merc. & Passivo/Ativo & MTB & Vol.Neg. & Conc.Acion. & ETR \\
\hline Média & 14,39 & 55,66 & 0,67 & 8,85 & 33,70 & 0,35 \\
Mediana & 14,30 & 52,80 & 0,59 & 8,65 & 32,01 & 0,29 \\
Desvio padrão & 1,46 & 15,34 & 0,29 & 1,39 & 13,68 & 0,30 \\
Intervalo & 6,61 & 72,58 & 1,44 & 4,58 & 55,34 & 1,30 \\
Mínimo & 11,25 & 30,70 & 0,24 & 6,86 & 11,16 & $-0,05$ \\
Máximo & 17,86 & 103,28 & 1,68 & 11,44 & 66,50 & 1,26 \\
\hline
\end{tabular}

Painel B - Estatística descritiva para o grupo label adopters

\begin{tabular}{lcccccc}
\hline & Valor Merc. & Passivo/Ativo & MTB & Vol.Neg. & Conc.Acion. & ETR \\
\hline Média & 13,84 & 53,61 & 0,65 & 7,26 & 80,41 & 0,19 \\
Mediana & 14,09 & 53,63 & 0,65 & 6,94 & 87,06 & 0,25 \\
Desvio padrão & 1,69 & 14,32 & 0,31 & 1,47 & 16,91 & 0,23 \\
Intervalo & 7,34 & 79,60 & 1,81 & 6,33 & 56,13 & 1,32 \\
Mínimo & 9,41 & 3,10 & 0,10 & 4,70 & 43,87 & $-0,74$ \\
Máximo & 16,74 & 82,70 & 1,91 & 11,03 & 100,00 & 0,58 \\
\hline
\end{tabular}

Fonte: Elaboração Própria.

Definições: Valor Merc. é definido como o logaritmo natural da média do valor de mercado da empresa no ano de 2007; Passivo/Ativo é definido como a razão entre o passivo total e o ativo da empresa no ano de 2007; MTB é a razão market-to-book da empresa no ano de 2007; Vol.Neg. é o logaritmo natural da média do volume de negociação da empresa no ano de 2007; Conc.Acion. é definida como a soma dos dois maiores acionistas com direito a voto; ETR é definida como a razão entre a despesa corrente de IRPJ/CSSL e o Lucro antes do IRPJ/CSSL (LAIR);

Serious Adopters = subgrupo de empresas com maior monitoramento do mercado acionário;

Label Adopters = subgrupo de empresas com menor monitoramento do mercado acionário;

Em geral, as médias e medianas das variáveis de interesse são consistentes com as predições. Mais especificamente, as médias e as medianas das variáveis valor de mercado, volume de negociação e alíquota efetiva de IR/CS são superiores para o grupo serious adopters em relação ao grupo label adopters. Além disso, a média e a mediana da variável concentração acionária são menores para o grupo serious adopters em relação ao grupo label adopters. Esses resultados são consistentes com um maior monitoramento do mercado acionário sobre o grupo serious adopters, que por sua vez provoca uma demanda por informação contábil de qualidade superior.

As medidas de desvio-padrão e intervalo entre extremos não revelam uma maior dispersão das variáveis para o grupo label adopters ou para o grupo serious adopters. 
Enquanto que os desvios-padrão das variáveis razão passivo/ativo e alíquota efetiva de IR/CS são superiores para o grupo serious adopters, os desvios-padrão das demais variáveis são superiores para o grupo label adopters.

\subsection{RESULTADOS PARA OS TESTES DE QUALIDADE DA INFORMAÇÃO CONTÁBIL}

\subsubsection{Resultados para o Modelo Reverso de Lucros Associados a Retornos para os três grupos de empresas antes da adoção de IFRS}

A tabela 10 apresenta os resultados da avaliação de conservadorismo condicional para os três grupos de empresas no período de 2003 a 2007.

Tabela 10 - Regressões para o Modelo Reverso de Lucros Associados a Retornos para os três grupos de empresas no período de 2003 a 2007.

$$
E_{A R N_{i t}}=\alpha+\beta_{1} \mathrm{DR}_{\mathrm{it}}+\beta_{2} \operatorname{Ret}_{\mathrm{it}}+\beta_{3} \mathrm{DR}_{\mathrm{it}} * \mathrm{Ret}_{\mathrm{it}}+\varepsilon_{\mathrm{jt}}
$$

\begin{tabular}{|c|c|c|c|c|c|c|c|}
\hline \multirow[b]{3}{*}{ Variável } & \multicolumn{3}{|c|}{$A D R$} & \multicolumn{2}{|c|}{ Serious Adopters } & \multicolumn{2}{|c|}{ Label Adopters } \\
\hline & \multicolumn{2}{|c|}{ Coeficiente } & \multirow[t]{2}{*}{ Valor-P } & Coeficiente & \multirow[t]{2}{*}{ Valor-P } & Coeficiente & \multirow[t]{2}{*}{ Valor-P } \\
\hline & & & & & & & \\
\hline Intercepto & 0,431 & & 0,000 & 0,982 & 0,000 & $0,785 * * *$ & 0,000 \\
\hline $\mathrm{DR}_{\text {it }}$ & 0,617 & $* * *$ & 0,617 & $-0,293$ & 0,235 & $-0,169$ & 0,816 \\
\hline $\operatorname{Ret}_{\mathrm{it}}$ & $-0,026$ & & $-0,026$ & $-0,228$ & 0,394 & $1,428 \quad * * *$ & 0,004 \\
\hline $\operatorname{Ret}_{i t} * \mathrm{DR}_{\mathrm{it}}$ & 1,524 & $*$ & 1,524 & 0,684 & 0,624 & $-4,294$ & 0,175 \\
\hline $\mathrm{n}$ & 459 & & 459 & 467 & & 2912 & \\
\hline R-quadrado & $4,2 \%$ & & $4,2 \%$ & $0,8 \%$ & & $0,3 \%$ & \\
\hline R-quadrado Ajustado & $3,5 \%$ & & $3,5 \%$ & $0,2 \%$ & & $0,2 \%$ & \\
\hline Estatística F & 6,6 & $* * *$ & 6,6 & 1,2 & 0,296 & $3,1 \quad * *$ & 0,03 \\
\hline \multicolumn{8}{|c|}{$\begin{array}{l}\text { Asteriscos *, ** } \mathrm{e} * * * \text { denotam significância estatística bicaudal à } 10 \%, 5 \% \text { e } 1 \% \text { respectivamente. } \\
\text { Definições: } \\
E A R N_{i t} \text { é o resultado por ação da empresa i para o ano } \mathrm{t} \text {; Ret }{ }_{\mathrm{it}} \text { é o retorno do preço da ação para a empresa i no ano } \mathrm{t} ; \mathrm{DR}_{\mathrm{it}} \text { é uma } \\
\text { dummy que assume } 1 \text { quando o retorno da ação é negativo e } 0 \text { caso contrário; } \\
\text { ADR = grupo de empresas com ADR's antes de } 2008 ; \\
\text { Serious Adopters = subgrupo de empresas com maior monitoramento do mercado acionário; } \\
\text { Label Adopters = subgrupo de empresas com menor monitoramento do mercado acionário; }\end{array}$} \\
\hline
\end{tabular}


Os resultados do teste de conservadorismo condicional antes da adoção do IFRS são consistentes com as predições feitas anteriormente. $O$ coeficiente $\beta_{3}$ não é estatisticamente significante seja para o grupo serious adopters seja para o grupo label adopters. Assim, não é possível afirmar que esses dois conjuntos de empresas adotavam mecanismos de reconhecimento tempestivo das perdas econômicas antes da adoção de IFRS. Argumenta-se que esse grupo de empresas não possuía incentivos suficientes para adotar mecanismos de conservadorismo condicional.

Esses resultados corroboram com estudos empíricos nacionais que buscaram investigar o conservadorismo antes de 2008. Utilizando uma amostra de empresas brasileiras no período de 1995 a 1999, Lopes (2001) identifica que as perdas econômicas não são reconhecidas oportunamente, mensurando tal reconhecimento pelo modelo de mercado de Basu (1997). Rangel e Teixeira (2003) analisam dados contábeis referentes ao período 1998/2001 relativos a empresas de capital aberto do setor de siderurgia e metalurgia e encontram que essas firmas não elaboram números contábeis com prudência. Costa et al. (2006) aplicam o mesmo modelo de Basu (1997) para amostra de companhias abertas latino-americanas compreendendo o período de 1995 a 2001 e encontram que a contabilidade não incorpora significativamente o retorno econômico.

Por outro lado, o coeficiente $\beta_{3}$ das empresas do grupo ADR é positivo e estatisticamente significante, evidenciando que essas empresas adotavam mecanismos de reconhecimento tempestivo das perdas econômicas mesmo antes da adoção de IFRS.

Esse resultado corrobora com evidências de outros estudos. Hail e Leuz (2006) encontram que empresas estrangeiras que emitem ADR's possuem maior qualidade da informação contábil em relação aquelas do país de origem que não emitiram títulos no mercado norte americano. Lang, Lins e Maffett (2012) encontram que as medidas de gerenciamento de resultado são menores para empresas que possuem títulos negociados nas bolsas de valores norte americanas. Além disso, encontram que as ações de empresas com ADR's possuem um aumento de liquidez e redução do custo de capital ao longo do tempo.

Dos resultados obtidos com o teste de conservadorismo, destacam-se a validação da variável $A D R$ para identificar um grupo com qualidade da informação contábil superior 
antes de 2008, bem como a não verificação de conservadorismo condicional para o grupo serious adopters antes de 2008. Assim, para identificar se ocorreu incremento de qualidade para o grupo serious adopters, há a necessidade de testar o conservadorismo condicional desse grupo após 2008.

\subsubsection{Resultados para o Modelo de Value Relevance para os três grupos de empresas antes da adoção de IFRS}

A tabela 11 apresenta os resultados da avaliação de value relevance para os três grupos de empresas no período de 2003 a 2007.

Tabela 11 - Regressões para o modelo de Value Relevance para os três grupos de empresas no período de 2003 a 2007

\begin{tabular}{|c|c|c|c|c|c|c|c|}
\hline \multicolumn{8}{|c|}{$R E T_{i t+1}=\alpha+\beta_{1} L A I R_{i t}+\varepsilon_{i t}$} \\
\hline & \multicolumn{3}{|c|}{$A D R$} & \multicolumn{2}{|c|}{ Serious Adopters } & \multicolumn{2}{|c|}{ Label Adopters } \\
\hline & Coeficie & nte & Valor-P & Coeficiente & Valor-P & Coeficiente & Valor-P \\
\hline \multicolumn{8}{|l|}{ Variável } \\
\hline Intercepto & 0,046 & & 0,000 & 0,079 & 0,000 & $0,133 * * *$ & 0,000 \\
\hline$L A I R_{i t}$ & 1,031 & $* * *$ & 0,003 & 0,484 & 0,114 & 0,041 & 0,535 \\
\hline $\mathrm{N}$ & 533 & & & 481 & & 2991 & \\
\hline R-quadrado & $1,66 \%$ & & & $0,5 \%$ & & $0,01 \%$ & \\
\hline R-quadrado Ajustado & $1,47 \%$ & & & $0,3 \%$ & & $0,01 \%$ & \\
\hline Estatística F & 8,9 & $* * *$ & 0,003 & 2,5 & 0,114 & 0,4 & 0,535 \\
\hline \multicolumn{8}{|c|}{$\begin{array}{l}\text { Asteriscos *,** e *** denotam significância estatística bicaudal à } 10 \%, 5 \% \text { e } 1 \% \text { respectivamente. } \\
\text { Definições: } \\
R E T_{i+1 t} \text { é o retorno da ação i } 3 \text { meses após a divulgação das demonstrações financeiras; e } L A I R_{i t} \text { é o valor do lucro antes do } \\
\text { imposto de renda, dividido pelo total de ativos. } \\
A D R=\text { grupo de empresas com ADR's antes da } 2008 ; \\
\text { Serious Adopters = subgrupo de empresas com maior monitoramento do mercado acionário; } \\
\text { Label Adopters = subgrupo de empresas com menor monitoramento do mercado acionário; }\end{array}$} \\
\hline
\end{tabular}

O modelo de relevância permite investigar a qualidade da informação contábil, ou ainda, a sua relevância para o mercado de capitais. A informação contábil é relevante ao apresentar alguma associação com o valor de mercado do capital ou preço das ações (BARTH; BEAVER; LANDSMAN, 2001). 
Em virtude da não significância do coeficiente $\beta_{2}$, não é possível verificar a existência de value relevance seja para o grupo serious adopters seja para o grupo label adopters antes de 2008. Assim, essas empresas não teriam incentivos suficientes em divulgar informações contábeis que ajudassem os investidores a formarem expectativas em relação à formação dos fluxos de caixa futuros. De forma similar, Nakao (2012) não encontra value relevance do LAIR antes de 2008 tanto para as empresas pertencentes ao Ibovespa quanto para as empresas não pertencentes ao Ibovespa.

Por outro lado, o coeficiente $\beta_{2}$ das empresas do grupo ADR é positivo e estatisticamente significante, trazendo evidência de que o resultado divulgado pela empresa seria considerado relevante pelo investidor para avaliar o desempenho econômico-financeiro de uma entidade e seria refletido nos preços de mercado. De forma similar, Bailey, Karolyi e Salva (2006) encontram que a reação no retorno das ações e no volume negociado após um anúncio de lucros aumentou quando a empresa passou a emitir ADR's.

As conclusões alcançadas com os resultados do teste de value relevance são semelhantes às obtidas com o teste de conservadorismo condicional. Destacam-se a validação da variável $A D R$ como proxy de qualidade superior antes de 2008 , bem como a não verificação de value relevance do lucro contábil para o grupo serious adopters antes de 2008. Assim, para identificar se ocorreu incremento de qualidade para o grupo seriuos adopters, há a necessidade de testar a value relevance desse grupo após 2008.

\subsubsection{Resultados para o Modelo Reverso de Lucros Associados a Retornos para os três grupos de empresas após a adoção do IFRS}

A tabela 12 apresenta os resultados da avaliação de conservadorismo condicional para os três grupos de empresas no período de 2008 a 2014. Todas as regressões apresentam-se estatisticamente significantes. 
Tabela 12 - Regressões para o Modelo Reverso de Lucros Associados a Retornos para os três grupos de empresas no período de 2008 a 2014

$$
E_{A R N_{i t}}=\alpha+\beta_{1} \mathrm{DR}_{\mathrm{it}}+\beta_{2} \text { Ret }_{\mathrm{it}}+\beta_{3} \mathrm{DR}_{\mathrm{it}} * \mathrm{Ret}_{\mathrm{it}}+\varepsilon_{\mathrm{jt}}
$$

\begin{tabular}{|c|c|c|c|c|c|c|c|}
\hline \multirow[b]{3}{*}{ Variável } & \multicolumn{3}{|c|}{$A D R$} & \multicolumn{2}{|c|}{ Serious Adopters } & \multicolumn{2}{|c|}{ Label Adopters } \\
\hline & \multicolumn{2}{|c|}{ Coeficiente } & \multirow[t]{2}{*}{ Valor-P } & Coeficiente & \multirow[t]{2}{*}{ Valor-P } & \multirow[t]{2}{*}{ Coeficiente } & \multirow[t]{2}{*}{ Valor-P } \\
\hline & & & & & & & \\
\hline Intercepto & 0,802 & & 0,000 & $0,772 * * *$ & 0,000 & $0,654 * * *$ & 0,002 \\
\hline $\mathrm{DR}_{\text {it }}$ & 0,032 & & 0,800 & $-0,298 * * *$ & 0,001 & $-0,323$ & 0,328 \\
\hline Ret $_{\text {it }}$ & $-0,167$ & & 0,684 & $-0,238$ & 0,205 & $-0,046$ & 0,918 \\
\hline $\operatorname{Ret}_{i t} * \mathrm{DR}_{\mathrm{it}}$ & 2,839 & $* * *$ & 0,000 & $1,019 * *$ & 0,015 & 1,588 & 0,197 \\
\hline $\mathrm{N}$ & 672 & & & 911 & & 5251 & \\
\hline R-quadrado & $6,2 \%$ & & & $3,8 \%$ & & $0,1 \%$ & \\
\hline R-quadrado Ajustado & $5,8 \%$ & & & $3,5 \%$ & & $0,1 \%$ & \\
\hline Estatística F & 14,8 & $* * *$ & 0,000 & $12,0 \quad * * *$ & 0,000 & $2,3 *$ & 0,07 \\
\hline $\begin{array}{l}\text { Asteriscos *, ** } \mathrm{e}^{* * *} \text { denot } \\
\text { Definiçôes: } \\
\text { EARN }_{\text {it }} \text { é o resultado por aç } \\
\text { dummy que assume } 1 \text { quand } \\
\text { ADR = grupo de empresas c } \\
\text { Serious Adopters = subgrup } \\
\text { Label Adopters = subgrupo }\end{array}$ & $\begin{array}{l}\text { n significânci } \\
\text { da empresa } \\
\text { retorno da a } \\
\text { ADR's ante } \\
\text { de empresas c } \\
\text { empresas co }\end{array}$ & $\begin{array}{l}\text { a i para } \\
\text { ação é } 1 \\
\text { ecs de } 2 \\
\text { com m } \\
\text { om men }\end{array}$ & $\begin{array}{l}\text { ística bicauc } \\
\text { o ano t; Ret } \\
\text { negativo e } 0 \\
\text { 008; } \\
\text { aior monitor } \\
\text { or monitora }\end{array}$ & $\begin{array}{l}10 \%, 5 \% \text { e } 1 \% \text { res } \\
\text { retorno do preço } \\
\text { contrário; } \\
\text { to do mercado aci } \\
\text { o do mercado acio }\end{array}$ & $\begin{array}{l}\text { ectivamente. } \\
\text { da ação para } \\
\text { onário; } \\
\text { nário; }\end{array}$ & presa i no an & $\mathrm{DR}_{\mathrm{it}}$ é uma \\
\hline
\end{tabular}

As empresas que emitiram ADR apresentam conservadorismo condicional após a adoção das normas internacionais (coeficiente $\beta_{3}$ positivo e estatisticamente significante), indicando que a contabilidade antecipou registros de perdas já incorporadas aos preços das ações. Quando tomado em conjunto os resultados da tabela 12 com os resultados da tabela 10, depreende-se que o grupo de empresas com ADR continuam utilizando mecanismos de conservadorismo condicional em suas demonstrações financeiras após a adoção do padrão IFRS.

Após a adoção do padrão IFRS, o grupo de empresas serious adopters passa a apresentar reconhecimento tempestivo das perdas econômicas. $O$ coeficiente $\beta_{3}$ é estatisticamente significante e positivo, consistente com o reconhecimento mais tempestivo das perdas do que dos ganhos econômicos. Esses resultados sugerem que essas empresas passaram por um incremento de qualidade provavelmente em função da demanda por informação pelo mercado acionário. 
Já para o grupo de empresas label adopters não foi verificado qualquer mudança no conservadorismo condicional após a adoção do padrão IFRS, uma vez que o coeficiente $\beta_{3}$ é não estatisticamente significante. Os baixos incentivos econômicos para a divulgação de uma informação contábil de maior qualidade implicam em uma ausência de conservadorismo condicional mesmo com a adoção de normas orientadas à proteção do investidor.

Ao investigar o efeito da Lei $11.638 / 07$ sobre o conservadorismo condicional das empresas listadas na Bovespa, Santos et al (2011) não encontraram efeito das novas regras sobre o grau de reconhecimento assimétrico de perdas e ganhos. Ao contrário do estudo citado, os resultados obtidos neste trabalho fornecem evidência de conservadorismo condicional pelo menos para um determinado conjunto de empresas. Há de se ressaltar que a comparação entre os trabalhos fica prejudicada, uma vez que esse trabalho utilizou uma janela temporal superior ao referido trabalho, cujos dados foram coletados durante o período de 2006 a 2009.

\subsubsection{Resultado para o Modelo de Accruals Discricionários de Kothari, Leone e Wasley (2005) para os três grupos de empresas após a adoção do IFRS}

As tabelas 13, 14 e 15 apresentam os resultados da avaliação de gerenciamento de resultados para os três grupos de empresas.

Tabela 13 - Estatística descritiva dos accruals discricionários para os três grupos de empresas antes e após 2008

\begin{tabular}{|c|c|c|c|c|c|c|}
\hline \multirow[b]{3}{*}{ Estatísticas } & \multicolumn{2}{|c|}{$A D R$} & \multicolumn{2}{|c|}{ Serious Adopters } & \multicolumn{2}{|c|}{ Label Adopters } \\
\hline & Antes 2008 & Após 2008 & Antes 2008 & Após 2008 & Antes 2008 & Após 2008 \\
\hline & & & & & & \\
\hline Mediana & $-0,010$ & $-0,009$ & $-0,010$ & $-0,003$ & $-0,008$ & $-0,007$ \\
\hline Desvio Padrão & 0,088 & 0,091 & 0,147 & 0,121 & 0,153 & 0,159 \\
\hline Assimetria & 1,467 & 1,484 & 0,439 & $-0,237$ & $-0,462$ & 0,671 \\
\hline Intervalo & 0,759 & 1,095 & 1,284 & 0,846 & 2,188 & 2,186 \\
\hline $\begin{array}{l}\text { Definições: } \\
\text { ADR= grupo de en } \\
\text { Serious Adopters = } \\
\text { Label Adopters }=\end{array}$ & $\begin{array}{l}\text { ADR's antes } \\
\text { e empresas co } \\
\text { empresas com }\end{array}$ & $\begin{array}{l}2008 ; \\
\text { maior monit } \\
\text { enor monito }\end{array}$ & $\begin{array}{l}\text { to do merc } \\
\text { do merca }\end{array}$ & $\begin{array}{l}\text { cionário; } \\
\text { onário; }\end{array}$ & & \\
\hline
\end{tabular}


Tabela 14 - Teste ANOVA da distribuição dos accruals discricionários para os três grupos de empresas antes e após 2008

\begin{tabular}{|c|c|c|c|c|c|c|}
\hline & \multicolumn{2}{|c|}{ ADR } & \multicolumn{2}{|c|}{ Serious Adopters } & Label Adopters \\
\hline & & Antes 2008 & Após 2008 & Antes 2008 & Após 2008 & Antes 2008 Após 2008 \\
\hline \multirow{2}{*}{ ADR } & Antes 2008 & & & & & \\
\hline & Após 2008 & $1,01(0,28)$ & & & & \\
\hline \multirow{2}{*}{ Serious } & Antes 2008 & $3,6(0,00)$ & & & & \\
\hline & Após 2008 & & $0,95(0,96)$ & $1,23(0,15)$ & & \\
\hline \multirow{2}{*}{ Label } & Antes 2008 & $4,1(0,00)$ & & $1,19(0,40)$ & & \\
\hline & Após 2008 & & $10,2(0,00)$ & & $10,2(0,00)$ & $1,17(0,32)$ \\
\hline \multicolumn{7}{|c|}{$\begin{array}{l}\text { Definições: } \\
\text { ADR = grupo de empresas com ADR's antes de 2008; } \\
\text { Serious Adopters = subgrupo de empresas com maior monitoramento do mercado acionário; } \\
\text { Label Adopters = subgrupo de empresas com menor monitoramento do mercado acionário; } \\
\text { A hipótese nula do teste ANOVA é de que as variâncias de duas amostras são iguais. A rejeição da hipótese nula, ou seja, a } \\
\text { significância estatística do coeficiente permite afirmar que a variância entre as amostras são diferentes. } \\
\text { O valor na tabela fora dos parênteses é a estatística t do teste ANOVA. O valor entre parênteses expressa o p-valor bicaudal. }\end{array}$} \\
\hline
\end{tabular}

Segundo Coelho (2007), a maior dispersão da distribuição dos resíduos é um forte indício de qualidade inferior via gerenciamento de accruals discricionários. Do ponto de vista da análise dos resíduos, verifica-se que a dispersão da distribuição das apropriações discricionárias é maior entre as empresas label adopters, bem como para as empresas serious adopters antes da adoção do padrão IFRS. Isso pode ser verificado tanto medida pelo desvio padrão quanto pelo intervalo entre os extremos. Enquanto o desvio padrão dos grupos serious adopters e label adopters é de aproximadamente 15\%, o desvio padrão para o grupo $A D R$ é de $9 \%$. Os resultados do teste ANOVA indicam que a diferença entre o desvio-padrão do grupo $A D R$ e do grupo serious adopters antes de 2008 é estatisticamente significante (estatística t $=3,6$ e p-valor $=0,000$ ). Além disso, os desvios-padrões do grupo $A D R$ e do grupo label adopters são estatisticamente diferentes antes de 2008 (estatística t $=4,1$ e p-valor $=0,000$ ).

Não é possível verificar mudanças significativas na dispersão dos resíduos após 2008 tanto para o grupo ADR quanto para o grupo label adopters. O desvio padrão do grupo label adopters é de aproximadamente $15 \%$ e o desvio padrão para o grupo ADR é aproximadamente de $9 \%$ tanto antes quanto após 2008. Os resultados do teste ANOVA não indicam diferenças estatisticamente significantes do desvio-padrão antes e após 2008 para esses dois grupos. 
É verificada uma redução na dispersão dos resíduos para o grupo serious adopters após 2008. Entretanto, ao aplicar o teste ANOVA para o desvio-padrão desse grupo, não foi encontrada diferença estatisticamente significante para o desvio-padrão antes e após 2008 (estatística $\mathrm{t}=1,23$ e p-valor =0,15). Assim, não é possível afirmar que esse conjunto de empresas reduziu o gerenciamento de resultados após 2008.

Tabela 15 - Regressões para o modelo de accruals discricionários para os três grupos de empresas após 2008

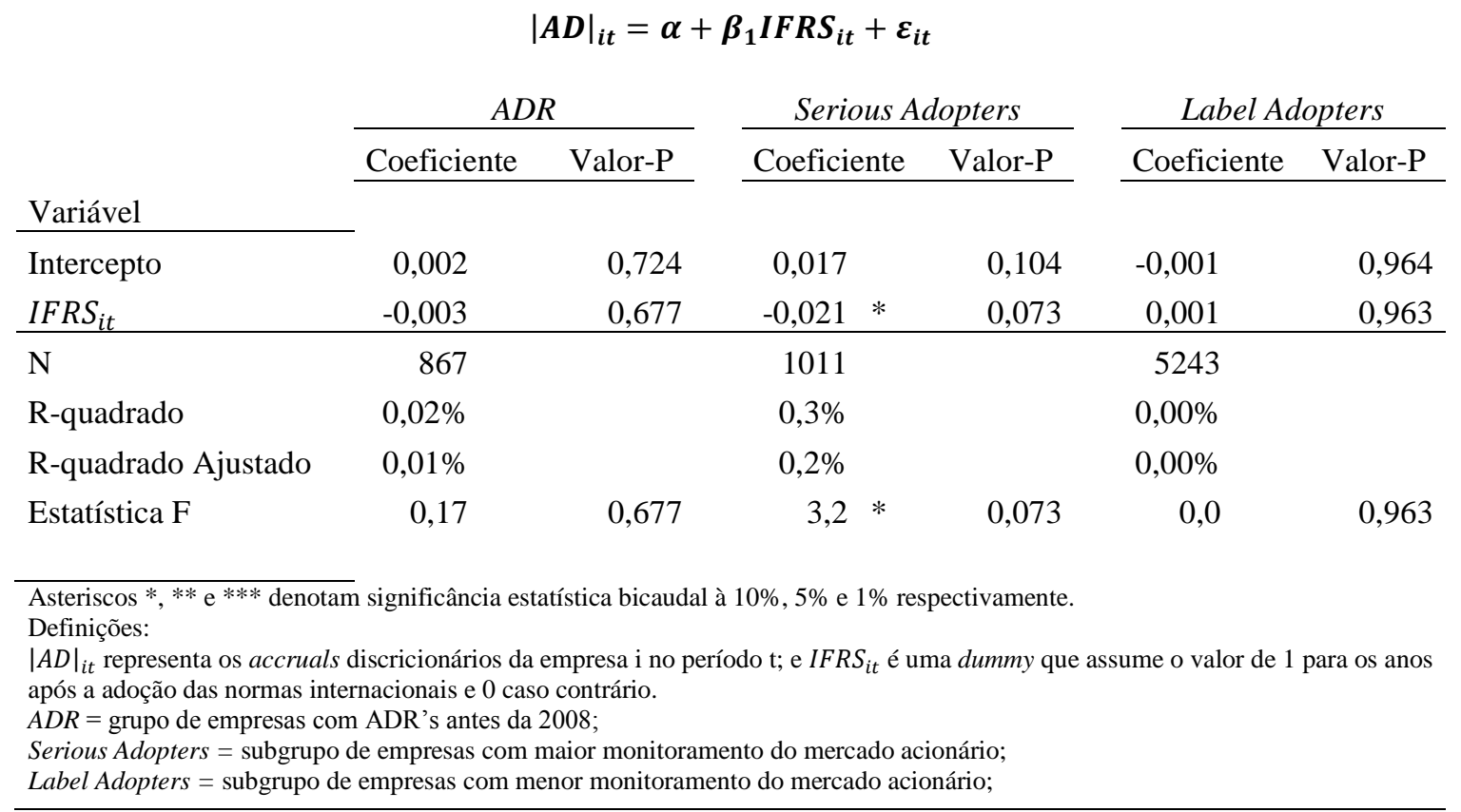

Ao contrário do resultado do teste ANOVA da tabela 13, foi identificada a redução no gerenciamento de resultados para o grupo serious adopters após a adoção do padrão IFRS. O coeficiente $\beta_{1}$ é estatisticamente significante e negativo, consistente com uma redução no gerenciamento de resultados evidenciando, assim, uma preocupação dessas empresas em trazer informação mais fidedigna para os investidores.

Além disso, não foi verificada redução no gerenciamento de resultados tanto para o grupo com baixos incentivos para divulgar uma informação de maior qualidade quanto para o grupo ADR. Esses resultados são consistentes com os resultados das tabelas $13 \mathrm{e}$ 14. 
Com base na dispersão dos resíduos (tabelas 13 e 14) do grupo ADR antes de 2008, depreende-se que esse grupo de empresas possui menor gerenciamento de resultados quando comparado com as demais empresas listadas na BOVESPA. A não verificação de redução de gerenciamento de resultados após 2008 pode ser vista como uma evidência de manutenção no nível de gerenciamento de resultados.

Como a dispersão dos resíduos do grupo label adopters antes de 2008 é relativamente alta (tabela 13) e não foi verificado redução do nível de gerenciamento de resultados (tabela 15), conclui-se que esse conjunto de empresas utilizou accruals discrionários para gerenciar resultados de acordo com sua necessidade antes e após 2008.

Não é possível verificar uma convergência dos resultados encontrados na literatura nacional de gerenciamento de resultados após a adoção do padrão IFRS. Os resultados de Joia e Nakao (2014) não permitem afirmar que tenha ocorrido uma queda no nível de gerenciamento de resultados com a introdução das normas IFRS. Klann (2011), por outro lado, registra que no Brasil no período pós-convergência houve um aumento do patamar de gerenciamento de resultados, comportamento diferente de que o autor identificou para a Inglaterra onde teria ocorrido uma diminuição do gerenciamento de resultados. Já Silva (2013) encontra que os accruals discricionários, proxy para GR, diminuíram no período da adoção completa.

Os resultados de não redução no gerenciamento de resultados do grupo $A D R$ e do grupo label adopters, bem como de evidência moderada de redução de gerenciamento de resultados do grupo serious adopters após 2008 podem ajudar a explicar o conflito de resultados da literatura nacional. Apesar de ser encontrada apenas uma evidência moderada de redução de gerenciamento de resultado para o grupo serious adopters, conclui-se que a segregação das empresas em grupos ajuda a superar a limitação de tratar as empresas de maneira homogênea.

\subsubsection{Resultados para o modelo de Value Relevance para os três grupos de empresas após a adoção do IFRS}


A tabela 16 apresenta os resultados da avaliação de value relevance para os três grupos de empresas no período de 2008 a 2014.

Tabela 16 - Regressões para os modelos de Value Relevance para os três grupos de empresas no período de 2008 a 2014

\begin{tabular}{|c|c|c|c|c|c|c|c|}
\hline \multirow[b]{4}{*}{ Variável } & \multicolumn{5}{|c|}{$\operatorname{RET}_{i t+1}=\alpha+\beta_{1} L A I R_{i t}+\varepsilon_{i t}$} & & \\
\hline & \multicolumn{3}{|c|}{$A D R$} & \multicolumn{2}{|c|}{ Serious Adopters } & \multicolumn{2}{|c|}{ Label Adopters } \\
\hline & Coeficie & & Valor-P & \multirow{2}{*}{ Coeficiente } & \multirow{2}{*}{ Valor-P } & \multirow{2}{*}{ Coeficiente } & \multirow{2}{*}{ Valor-P } \\
\hline & \multicolumn{3}{|c|}{ 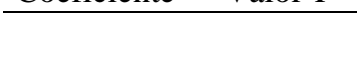 } & & & & \\
\hline Intercepto & $-0,009$ & & 0,355 & $-0,015 *$ & 0,099 & $0,011 * *$ & 0,021 \\
\hline$L A I R_{i t}$ & 1,678 & $* * *$ & 0,000 & $1,591 * * *$ & 0,000 & 0,001 & 0,932 \\
\hline $\mathrm{n}$ & 679 & & & 907 & & 5261 & \\
\hline R-quadrado & $4,7 \%$ & & & $4,8 \%$ & & $0,00 \%$ & \\
\hline R-quadrado Ajustado & $4,6 \%$ & & & $4,7 \%$ & & $0,00 \%$ & \\
\hline Estatística F & 33,8 & $* * *$ & 0,000 & $45,7 * * *$ & 0,000 & 0,001 & 0,932 \\
\hline \multicolumn{8}{|c|}{$\begin{array}{l}\text { Asteriscos *,** e *** denotam significância estatística bicaudal à } 10 \%, 5 \% \text { e } 1 \% \text { respectivamente. } \\
\text { Definições: } \\
R E T_{i+1 t} \text { é o retorno da ação i } 3 \text { meses após a divulgação das demonstrações financeiras; e } L A I R_{i t} \text { é o valor do lucro antes do } \\
\text { imposto de renda, dividido pelo total de ativos. } \\
\text { ADR = grupo de empresas com ADR's antes da } 2008 \text {; } \\
\text { Serious Adopters = subgrupo de empresas com maior monitoramento do mercado acionário; } \\
\text { Label Adopters = subgrupo de empresas com menor monitoramento do mercado acionário; }\end{array}$} \\
\hline
\end{tabular}

Em primeiro lugar, em função do coeficiente $\beta_{1}$ ser positivo e estatisticamente significante, o grupo com ADR apresenta value relevance do resultado contábil após da adoção do padrão IFRS.

Em segundo lugar, o grupo com incentivos econômicos para divulgar informação contábil de maior qualidade apresenta value relevance do lucro antes do IRRJ/CSSL após 2008. Somando-se ao fato da não verificação de value relevance antes de 2008 , conclui-se que o grupo serious adopters passou por um incremento de qualidade medido, dessa vez, pelo teste de value relevance.

Os resultados encontrados corroboram com os resultados da literatura nacional sobre value relevance e adoção do IFRS. Utilizando uma amostra de 2.277 observações trimestrais de todas as empresas que compuseram a carteira teórica do Ibovespa entre 1995 e 2009, Lima (2011) encontrou que a relevância da informação contábil mensurada através dos modelos de preço e retorno aumentou após a adoção das normas IFRS no Brasil. Utilizando dados de 2010 e 2011, Silva (2013) encontra value relevance 
da informação contábil durante o período de adoção completa do padrão IFRS. De maneira similar, os resultados de Gonçalves et al (2014) revelam que as informações contábeis se tornaram mais relevantes. A comparação entre os $\mathrm{R}^{2}$ das regressões de relevância revela que houve um incremento do poder de explicação do preço da ação por meio do LLPA (lucro líquido por ação) e do PLPA (patrimônio líquido por ação).

Por fim, não foi verificado value relevance para o grupo com baixos incentivos econômicos para divulgação de informação contábil de qualidade após da adoção das normas internacionais. Assim, essas empresas dificilmente exerceriam esforços para trazer informações contábeis que ajudassem os investidores a formarem expectativas em relação à formação dos fluxos de caixa futuros. Muito provavelmente, essas empresas tendem a possuir uma trajetória dependente às práticas contábeis anteriores com influência da tributação.

De forma similar, Nakao (2012) encontrou que as companhias que não pertenciam ao índice Ibovespa não apresentaram resultados significativos para value relevance antes ou após a adoção do padrão IFRS. O autor utiliza o Índice Ibovespa como proxy de pressão do mercado acionário por informação de maior qualidade.

\subsubsection{Testes de Robustez}

\subsubsection{Análise conjunta dos grupos que apresentam qualidade da informação contábil após a adoção do padrão IFRS}

Os resultados encontrados anteriormente levam à conclusão de que tanto o grupo $A D R$ quanto o grupo serious adopters possuem qualidade no conjunto das demonstrações contábeis após a adoção do padrão IFRS. Entretanto, foram verificadas evidências de qualidade de maneira individualiza e por motivações distintas para cada grupo de empresas. Assim, se os resultados são de fato consistentes, é natural supor que os resultados de qualidade informacional dos dois grupos sejam compatíveis com os resultados dos dois grupos de maneira conjunta após a adoção de IFRS. 


\subsection{Resultados para o Modelo Reverso de Lucros Associados a Retornos e Value Relevance para o grupo ADR e para o grupo serious adopters no período de 2008 a 2014}

A tabela 17 apresenta os resultados da avaliação de conservadorismo condicional para o grupo ADR e para o grupo serious adopters no período de 2008 a 2014.

Tabela 17 - Regressão para o Modelo Reverso de Lucros Associados a Retornos para o grupo $A D R$ e para o grupo serious adopters no período de 2008 a 2014

$$
E A R N_{i t}=\alpha+\beta_{1} D_{\text {it }}+\beta_{2} \text { Ret }_{i t}+\beta_{3} D_{\text {it }} * \operatorname{Ret}_{i t}+\varepsilon_{\text {jt }}
$$

ADR + Serious Adopters

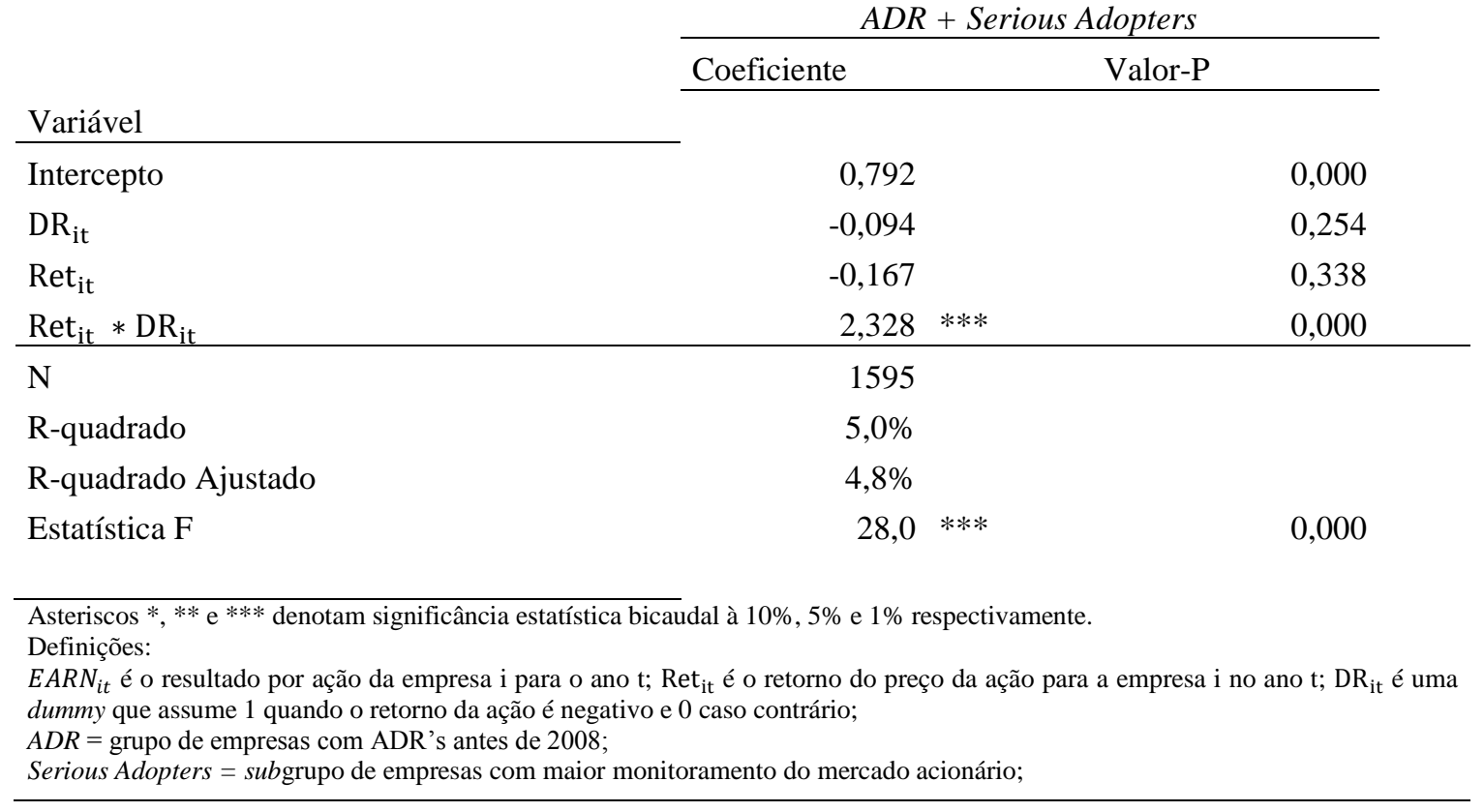

$\mathrm{O}$ coeficiente $\beta_{3}$ positivo e estatisticamente significante fornece evidência de conservadorismo condicional. Assim, o resultado de conservadorismo se mantém quando as empresas do grupo ADR e do grupo serious adopters são analisadas em conjunto.

A tabela 18 apresenta os resultados da avaliação de value relevance para o grupo ADR e para o grupo serious adopters no período de 2008 a 2014. 
Tabela 18 - Regressões para o modelo de Value Relevance para o grupo ADR e para o grupo serious adopters no período de 2008 a 2014

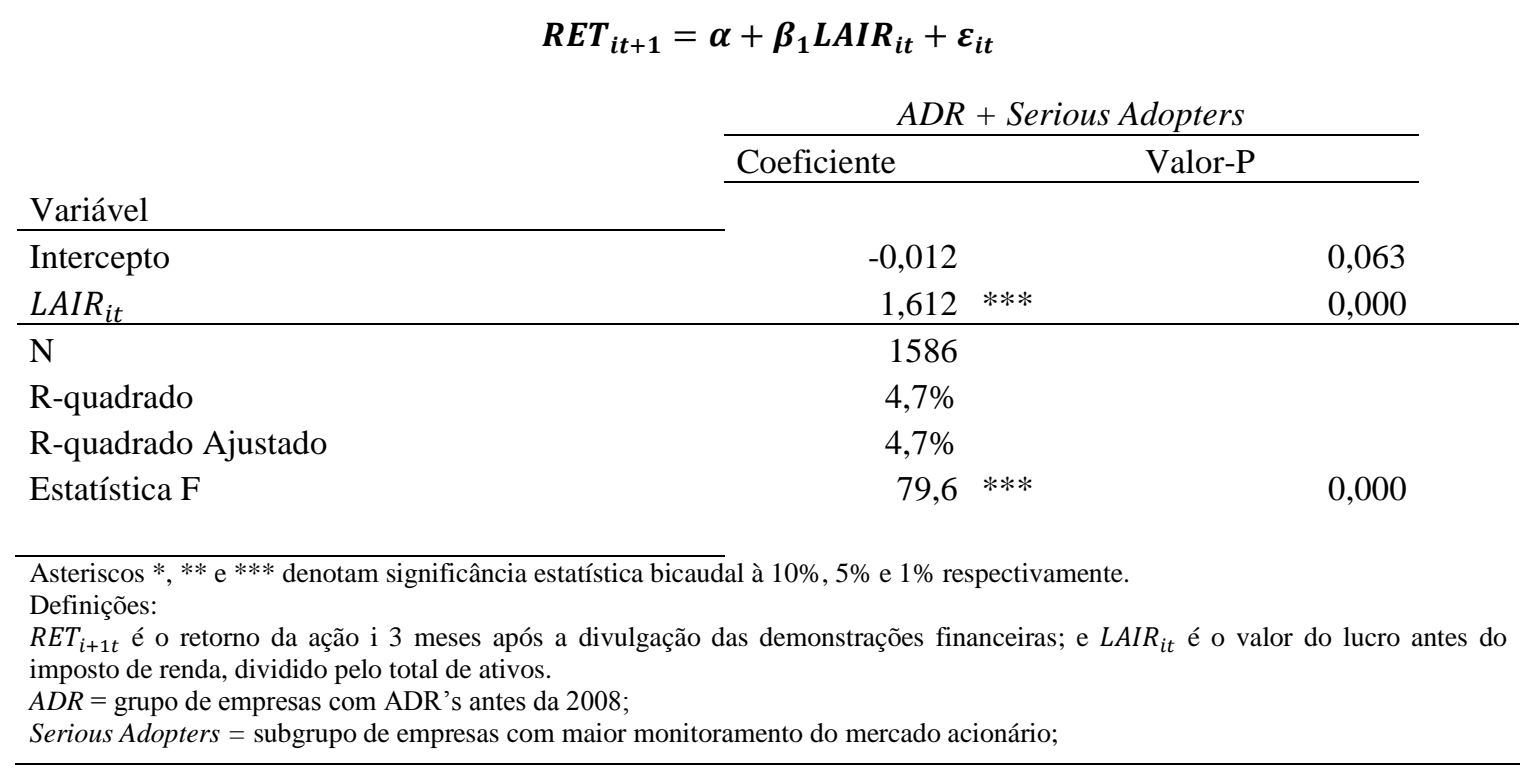

$\mathrm{O}$ coeficiente $\beta_{2}$ positivo e estatisticamente significante fornece evidência de value relevance da informação contábil. Assim, o resultado de relevância da informação contábil se mantém quando as empresas do grupo ADR e do grupo serious adopters são analisadas em conjunto.

Os resultados dos testes de conservadorismo e value relevance corroboram e fortalecem os resultados obtidos nos testes individuais dos grupos ADR e serious adopters. Com isso, esses resultados fortalecem o argumento de heterogeneidade na qualidade da informação contábil após 2008, afinal de contas, o restante das empresas listadas na BOVESPA não apresentam as características de conservadorismo e value relevance após a adoção do padrão IFRS.

\subsubsection{Efeito da desvinculação tributária sobre o ganho de qualidade após a adoção do IFRS}

Santana (2014) identifica um aumento significativo da BTD nos anos 2008 e 2009 com a instituição do RTT no final de 2007. A Book-Tax Differences (BTD), ou diferença 
contábil-tributária, corresponde à diferença entre o lucro contábil antes dos impostos (LAIR) e o lucro tributável apurado em conformidade com a legislação tributária.

Com a alteração dos critérios contábeis para o reconhecimento e mensuração de ativos e passivos, alguns acréscimos patrimoniais passaram a transitar pelo resultado a título de receita, sem que tivessem efeitos fiscais, como, por exemplo, algumas subvenções recebidas e ajustes a valor justo.

O mesmo fenômeno não ocorreu com o lucro tributável. Isto porque, quando da implementação do novo padrão contábil, a administração tributária federal instituiu o RTT - Regime Tributário de Transição -, através do qual ficou expressamente estabelecido na legislação que as alterações efetuadas nas normas contábeis nacionais em decorrência do alinhamento destas com o padrão contábil internacional não poderiam ter efeito algum sobre a apuração dos tributos, devendo esta apuração continuar a ser feita com os mesmos critérios que estavam vigentes em 31 de dezembro de 2007.

Além disso, nos anos de 2008 e 2009 está presente a adoção parcial de IFRS e, portanto, um período de adaptação à adoção das normas internacionais de contabilidade. Em dezembro de 2010, a CVM emitiu a deliberação nº 647 que exigiu a adoção do CPC 37 (R1) - Adoção Inicial das Normas Internacionais de Contabilidade - para as companhias abertas, iniciando a segunda etapa do processo de convergência. Este Pronunciamento Técnico é aplicado quando a entidade adota as IFRS pela primeira vez, e, naturalmente, exigiu a adoção de todos os CPCs e IFRSs vigentes em 2010 nas demonstrações contábeis consolidadas. Assim, a transição de GAAP é concluída, permitindo que as empresas divulguem seus relatórios contábeis full IFRS.

Com o fim da vinculação da legislação fiscal sobre a apuração do lucro contábil e com a adoção apenas parcial do padrão IFRS, é possível que o aumento de qualidade após 2007 possa ter se dado com o a desvinculação da contabilidade financeira da contabilidade tributária.

Apesar desse trabalho não ter por objetivo identificar a parcela de ganho informacional decorrente da adoção do padrão IFRS e da desvinculação financeira-fiscal, o início do 
RTT e adoção parcial de IFRS nos anos de 2008 e 2009 podem ter criado uma janela para começar a investigar essa pergunta.

A fim de trazer uma luz a essa questão, foi incluída uma dummy relativa aos anos de 2008 e 2009 nas regressões de value relevance e conservadorismo condicional, denominada RTT (Regime Tributário de Transição). Se o coeficiente dessa variável se mostrar significante e, ao mesmo tempo, o coeficiente de interesse da equação original deixar de apresentar significância estatística, ter-se-ia evidência do efeito da desvinculação financeira-fiscal sobre o ganho de qualidade após 2007. Visto de outra forma, fortalece o argumento de que o RTT e a consequente desvinculação das normas contábeis das normas tributárias exerce um papel fundamental sobre a qualidade da informação contábil, relativizando o efeito das normas IFRS.

A tabela 19 apresenta os resultados da avaliação de conservadorismo condicional para os três grupos de empresas no período de 2008 a 2014, incluindo a dummy RTT.

Tabela 19 - Regressões para o Modelo Reverso de Lucros Associados a Retornos para os três grupos de empresas no período de 2008 a 2014, incluindo a dummy RTT

$E A R N_{i t}=\alpha+\beta_{1} \mathrm{DR}_{\mathrm{it}}+\beta_{2} \operatorname{Ret}_{\mathrm{it}}+\beta_{3} \mathrm{DR}_{\mathrm{it}} * \operatorname{Ret}_{\mathrm{it}}+\beta_{4} \mathrm{RTT}_{\mathrm{it}}+\beta_{5} \mathrm{DR}_{\mathrm{it}} * \operatorname{Ret}_{\mathrm{it}} * \mathrm{RTT}_{\mathrm{it}}+\varepsilon_{\mathrm{jt}}$

\begin{tabular}{|c|c|c|c|c|c|c|c|}
\hline \multirow[b]{3}{*}{ Variável } & \multicolumn{3}{|c|}{$A D R$} & \multicolumn{2}{|c|}{ Serious Adopters } & \multicolumn{2}{|c|}{ Label Adopters } \\
\hline & \multicolumn{2}{|c|}{ Coeficiente } & \multirow[t]{2}{*}{ Valor-P } & Coeficiente & \multirow[t]{2}{*}{ Valor-P } & \multirow[t]{2}{*}{ Coeficiente } & \multirow[t]{2}{*}{ Valor-P } \\
\hline & & & & & & & \\
\hline Intercepto & 0,719 & & 0,000 & $0,478 * * *$ & 0,000 & $0,706 * * *$ & 0,002 \\
\hline $\mathrm{DR}_{\text {it }}$ & 0,198 & & 0,179 & $-0,071$ & 0,143 & $-0,308$ & 0,356 \\
\hline Ret $_{i t}$ & $-0,141$ & & 0,676 & $-0,089$ & 0,514 & $-0,026$ & 0,954 \\
\hline Ret $_{\text {it }} * \mathrm{DR}_{\text {it }}$ & 3,715 & $* * *$ & 0,000 & $1,119 * * *$ & 0,000 & 2,121 & 0,163 \\
\hline $\mathrm{RTT}_{\text {it }}$ & 0,312 & $* *$ & 0,019 & 0,052 & 0,422 & $-0,176$ & 0,593 \\
\hline $\mathrm{DR}_{\mathrm{it}} * \mathrm{Ret}_{\mathrm{it}} * \mathrm{RTT}_{\mathrm{it}}$ & 1,489 & & 0,111 & $-0,501$ & 0,131 & $-1,230$ & 0,505 \\
\hline $\mathrm{N}$ & 684 & & & 833 & & 5251 & \\
\hline R-quadrado & $9,2 \%$ & & & $5,9 \%$ & & $0,1 \%$ & \\
\hline R-quadrado Ajustado & $8,5 \%$ & & & $5,4 \%$ & & $0,1 \%$ & \\
\hline Estatística F & 13,8 & $* * *$ & 0,000 & $10,5 * * *$ & 0,000 & 1,5 & 0,18 \\
\hline
\end{tabular}

Asteriscos *, ** e *** denotam significância estatística bicaudal à $10 \%, 5 \%$ e $1 \%$ respectivamente.

Definições:

$E A R N_{i t}$ é o resultado por ação da empresa i para o ano t; Ret ${ }_{i t}$ é o retorno do preço da ação para a empresa i no ano t; $\mathrm{DR}_{\mathrm{it}}$ é uma dummy que assume 1 quando o retorno da ação é negativo e 0 caso contrário; $\mathrm{RTT}_{\text {it }}$ é uma dummy que assume 1 para os anos de 2008 e 2009 e 0 caso contrário.

$A D R=$ grupo de empresas com ADR's antes de 2008;

Serious Adopters $=$ subgrupo de empresas com maior monitoramento do mercado acionário;

Label Adopters = subgrupo de empresas com menor monitoramento do mercado acionário; 
Os resultados do coeficiente de conservadorismo, $\beta_{3}$, não alteraram as conclusões alcançadas do modelo sem a adição da dummy de RTT. Mais especificamente, o coeficiente $\beta_{3}$ se manteve positivo e estatisticamente significante para o grupo ADR e para o grupo serious adopters, evidenciando a presença de mecanismos de conservadorismo condicional nas demonstrações contábeis após 2008. Além disso, não foi possível encontrar conservadorismo condicional para as empresas label adopters, inclusive quando foi adicionada a dummy de RTT.

Nenhum dos coeficientes de interesse para analisar a desvinculação tributária-financeira sobre a qualidade da informação contábil, $\beta_{5}$, mostrou-se significante no modelo de conservadorismo condicional de Basu (1997).

A tabela 20 apresenta os resultados da avaliação de value relevance para os três grupos de empresas no período de 2008 a 2014, incluindo a dummy RTT.

Tabela 20 - Regressões para os modelos de Value Relevance para os três grupos de empresas no período de 2008 a 2014, incluindo a dummy RTT

\begin{tabular}{|c|c|c|c|c|c|c|c|}
\hline \multicolumn{8}{|c|}{$R_{E T} i t+1=\alpha+\beta_{1} L A I R_{i t}+\beta_{2} \mathrm{RTT}_{\mathrm{it}}+\beta_{3} L A I R_{i t} * \mathrm{RTT}_{\mathrm{it}}+\varepsilon_{i t}$} \\
\hline & Coeficien & nte & Valor-P & Coeficiente & Valor-P & Coeficiente & Valor-P \\
\hline \multicolumn{8}{|l|}{ Variável } \\
\hline Intercepto & $-0,023$ & & 0,063 & $-0,026 * * *$ & 0,009 & $-0,005$ & 0,374 \\
\hline$L A I R_{i t}$ & 1,778 & $* * *$ & 0,000 & $1,475 * * *$ & 0,000 & 0,002 & 0,826 \\
\hline$R T T_{\text {it }}$ & 0,041 & $* *$ & 0,045 & 0,037 & 0,072 & 0,055 & 0,000 \\
\hline$L A I R_{i t} * R T T_{i t}$ & $-0,135$ & & 0,818 & 0,404 & 0,487 & 0,001 & 0,979 \\
\hline $\mathrm{N}$ & 679 & & & 907 & & 5261 & \\
\hline R-quadrado & $5,4 \%$ & & & $5,7 \%$ & & $0,5 \%$ & \\
\hline R-quadrado Ajustado & $4,9 \%$ & & & $5,4 \%$ & & $0,4 \%$ & \\
\hline Estatística F & 12,7 & $* * *$ & 0,000 & $18,4 * * *$ & 0,000 & $8,9 * * *$ & 0,000 \\
\hline \multicolumn{8}{|c|}{$\begin{array}{l}\text { Asteriscos *,** e*** denotam significância estatística bicaudal à } 10 \%, 5 \% \text { e } 1 \% \text { respectivamente. } \\
\text { Definições: } \\
R E T_{i+1 t} \text { é o retorno da ação i } 3 \text { meses após a divulgação das demonstrações financeiras; e } L A I R_{i t} \text { é o valor do lucro antes do } \\
\text { imposto de renda, dividido pelo total de ativos; } \mathrm{RTT}_{\mathrm{it}} \text { é uma dummy que assume } 1 \text { para os anos de } 2008 \text { e } 2009 \text { e } 0 \text { caso contrário. } \\
A D R=\text { grupo de empresas com ADR's antes da } 2008 ; \\
\text { Serious Adopters = subgrupo de empresas com maior monitoramento do mercado acionário; } \\
\text { Label Adopters = subgrupo de empresas com menor monitoramento do mercado acionário; }\end{array}$} \\
\hline
\end{tabular}

A inclusão da dummy de RTT não afetou os resultados obtidos anteriormente. Por um lado, a variável LAIR apresenta value relevance tanto para o grupo ADR quanto para o 
grupo serious adopters, uma vez que o coeficiente $\beta_{1}$ se mostrou positivo e estatisticamente significante. Em contrapartida, não há significância estatística do coeficiente $\beta_{1}$ para o grupo de empresas label adopters, ou seja, não haveria value relevance do Lucro antes do IR após a adoção do padrão IFRS.

Nenhum dos coeficientes de interesse para analisar a desvinculação tributária-financeira sobre a qualidade da informação contábil, $\beta_{3}$, mostrou-se significante no modelo de value relevance.

Entretanto, a insignificância estatística não permite afirmar que a desvinculação tributária-financeira não teve impacto sobre a qualidade informacional após 2008. Em termos estatísticos, os anos de 2008 e 2009 estão inclusos no coeficiente $\beta_{3}$ (para o teste de conservadorismo condicional) e no coeficiente $\beta_{1}$ (para o teste de value relevance). Assim, os coeficientes $\beta_{5}$ (variável $\mathrm{DR}_{\mathrm{it}} * \operatorname{Ret}_{\mathrm{it}} * \mathrm{RTT}_{\mathrm{it}}$ ) e $\beta_{3}$ (variável $\operatorname{LAIR}_{i t} * R T T_{i t}$ ) estariam capturando simplesmente um efeito marginal. Além disso, os anos de 2008 e 2009 são reconhecidos como um período em que grande parte dos demonstrativos financeiros sofreu variações em decorrência da crise econômica mundial. A crise financeira impacta de maneira direta as variáveis de interesse - preço das ações e lucro líquido -, contaminando a análise do efeito da desvinculação sobre a qualidade da informação contábil.

A verificação da contribuição individual da desvinculação tributária-financeira e da adoção do padrão IFRS sobre a qualidade informacional está fora do escopo desse trabalho. De qualquer forma, os resultados desse trabalho indicam que existe mais de um direcionador da qualidade da informação contábil após 2007. A adoção do IFRS, a desvinculação da contabilidade financeira da contabilidade físcal, os incentivos econômicos individuais e a qualidade antes da adoção podem ser vistos, em conjunto, como direcionadores da qualidade da informação contábil. 


\section{CONSIDERAÇÕES FINAIS}

O objetivo desse trabalho foi investigar a existência de heterogeneidade no ganho de qualidade da informação contábil após a adoção do padrão. É analisado o caso do Brasil. Em primeiro lugar, as empresas listadas na BOVESPA foram separadas em dois grupos, a saber: empresas que emitiram ADR até o ano de 2008 e empresas que não emitiram ADR. Em seguida, as empresas que não emitiram ADR até o ano de 2008 foram separadas em dois subgrupos por meio de uma análise de conglomerados. O objetivo da análise de cluster foi separar as empresas com maior monitoramento do mercado acionário daquelas com menor monitoramento. Um maior monitoramento está associado com uma maior demanda por informação contábil de qualidade. Como o padrão IFRS é mais orientado ao mercado de capitais e mais abrangente em relação a grande parte dos PCGA nacionais, a empresa com maior monitoramento do mercado teria incentivo em aumentar a qualidade da informação contábil após a adoção do IFRS para sinalizar comprometimento e transparência para o mercado.

Em geral, os resultados dos testes são consistentes com as predições. As empresas com incentivos econômicos dados pelo mercado acionário realmente alcançam um incremento de qualidade após a adoção do padrão IFRS. Esse conjunto de empresas passa a ter um reconhecimento mais tempestivo das perdas em relação aos ganhos econômicos, passam a ter o lucro divulgado como uma variável value relevant $\mathrm{e}$ possuem evidência moderada de redução no gerenciamento de resultados. Esses resultados sugerem que a demanda do mercado acionário por informação contábil de maior qualidade, o ensejo dessas empresas de realizar captações no mercado e a adoção de IFRS possam ser vistos, em conjunto, como direcionadores da qualidade da informação contábil.

Além disso, foram encontradas evidências de qualidade da informação contábil para o grupo $A D R$. As empresas desse grupo possuem conservadorismo condicional, value relevance do lucro contábil e menor gerenciamento de resultados tanto antes quanto após 2008. A identificação de um grupo de empresas com qualidade superior prévia pode ser vista como uma contribuição desse trabalho. Afinal de contas, trabalhos empíricos internacionais identificaram a existência de apenas dois grupos de empresas 
(DASKE et al. 2013). Portanto, a verificação de um terceiro grupo, cuja característica diferenciadora seja sua qualidade antes da adoção do IFRS pode ser encarada como uma contribuição adicional desse trabalho.

Por fim, não foi identificada qualidade da informação contábil para o conjunto de empresas com baixos incentivos econômicos seja antes, seja após 2008. Muito provavelmente, essas empresas tendem a possuir uma trajetória dependente às práticas contábeis anteriores com influência da tributação.

Esse trabalho verificou que a adoção do padrão IFRS não pode ser visto como o único direcionador da qualidade da informação contábil. Em primeiro lugar, se a adoção do padrão IFRS fosse suficiente para aumentar a qualidade da informação contábil seria natural imaginar que houvesse uma convergência dos trabalhos nacionais empíricos que procuram verificar o ganho de qualidade após 2008. Pelo contrário, existe um conflito de resultados quando são analisados os trabalhos em conjunto. Assim, esse trabalho procura superar a limitação encontrada na literatura nacional de tratar as empresas de maneira homogênea, cujos resultados geralmente capturam o efeito médio das empresas em torno da adoção do padrão IFRS.

Os resultados encontrados nesse estudo indicam que a adoção do padrão IFRS, os incentivos econômicos para divulgar uma informação de maior qualidade, a desvinculação da contabilidade financeira da contabilidade tributária e a qualidade existente antes de 2008 podem ser vistas em conjunto como direcionadores da qualidade da informação contábil.

Os resultados contribuem com uma linha de pesquisa da literatura contábil a qual procura entender as reais motivações e incentivos por de trás da elaboração da informação contábil (Ball et al., 2000; 2003; Ball e Shivakumar, 2005; Bushman e Piotroski, 2006; Leuz et al., 2003 entre outros) ao mostrar que as variáveis no nível das empresas possuem um papel chave nesse processo.

Além disso, órgãos normatizadores nacionais e internacionais poderiam estar interessados nesses resultados, uma vez que mostram que as propriedades das demonstrações contábeis dependem dos incentivos no nível das empresas. Isso impõe um desafio para os recentes esforços desses órgãos em consolidar a convergência das 
normas contábeis no nível internacional. Os resultados sugerem que um conjunto global e uniforme de normas contábeis podem não ter um poder de facto para fazer com que as propriedades nos números contábeis convirjam para um mesmo nível.

Uma limitação desse trabalho seria a generalização dos resultados encontrados para outros países. Afinal de contas, a predição feita com cada grupo de empresas tem como pano de fundo o argumento de que os aspectos institucionais, culturais e históricos do país influenciaram a qualidade da informação contábil verificada. Como ilustração, o grupo $A D R$ tem como motivação, nesse trabalho, o baixo desenvolvimento do mercado de capitais brasileiro. Apesar dessa limitação, a pergunta de pesquisa pode ser replicada para outros países que adotaram IFRS, pois a literatura de incentivos de divulgação da informação contábil fornece sustentação para a hipótese de heterogeneidade no ganho de qualidade informacional.

Outro fator limitante durante a pesquisa foi a falta de dados disponíveis para empresas classificadas nos três grupos, principalmente, para as empresas classificadas no grupo label adopters.

A sugestão desse trabalho para pesquisas futuras baseia-se no teste que procurou identificar o impacto da desvinculação da contabilidade financeira da contabilidade tributária. A simplificação do teste realizado nesse trabalho implica em uma oportunidade para pesquisas futuras para procurar identificar a contribuição individual da desvinculação da contabilidade financeira da contabilidade tributária. Sugere-se a utilização de variáveis de controle numa tentativa de expurgar o efeito de outras variáveis sobre a desvinculação financeira-tributária, como por exemplo, os efeitos da crise de 2008 sobre os demonstrativos contábeis. 


\section{REFERÊNCIAS BIBLIOGRÁFICAS}

ALI, A. HWANG, L. Country specific factors related to financial reporting and the value relevance of accounting data. Journal of Accounting Research, 38, 2000.

ANDERSON, C.W. Financial contracting under extreme uncertainty: an analysis of Brazilian corporate debentures. Journal of Financial Economics, volume 51, Issue 1, Pages 45-84, 1999.

ANGELO, L. E. Accounting Numbers as Market Valuation Substitutes: A Study of Management Buyouts of Public Stockholders. The Accounting Review, vol. $61 \mathrm{n}^{\mathrm{o}} 3$, pp.400-420, 1986.

ASHBAUGH, H.; OLSSON, P. An Exploratory Study of the Valuation Properties of Cross-Listed Firms' IAS and U.S. GAAP Earnings and Book Values. The Accounting Review, vol. 77, No. 1, pp. 107-126, 2002.

AUBERT, F.; GRUDNITSKI, G. Analysts' estimates: what they could be telling us about the impact of IFRS on earnings manipulation in Europe. Review of Accounting and Finance, v. 11, n. 1, p. 53-72, 2012.

BAILEY, W.; KAROLYI, A. G.; SALVA, C. The Economic Consequences of Increased Disclosure: Evidence from International Cross-Listings," Working Paper Series 2004-7, Ohio State University, Charles A. Dice Center for Research in Financial Economics, 2006.

BALL, R. Infrastructure requirements for an economically efficient system of public financial reporting and disclosure. Brookings-Wharton Papers on Financial Services, 127-169, 2001.

BALL, R. International Financial Reporting Standards (IFRS): Pros and Cons for Investors. Accounting and Business Research: International Accounting Policy Forum, p. 5-27, 2006.

BALL, R.; KOTHARI, S. P.; ROBIN, A. The effect of international institutional factors on properties of accounting earnings. Journal of Accounting and Economics, 29, 1-51, 2000. 
BALL, R.; ROBIN, A.; WU, J. Incentives Versus Standards: Properties of Accounting Income in Four East Asian Countries. Journal of Accounting and Economics, v. 36, p. 235-270, 2003.

BALL, R.; SHIVAKUMAR, L. Earnings Quality in UK Private Firms: Comparative Loss Recognition Timeliness. Journal of Accounting \& Economics, 39: 83-128, 2005.

BALL, R.; SHIVAKUMAR, L. The Role of Accruals in Asymmetrically Timely Gain and Loss Recognition. Journal of Accounting Research,44: 207-42, 2006.

BARTH, M. E.; BEAVER, W. H.; LANDSMAN, W. R. The relevance of the value relevance literature for financial accounting standard setting: Another view. Journal of Accounting \& Economics. v. 31, No 1-3, 2001.

BARTH, M. E.; LANDSMAN, W. R.; LANG, M. H. International accounting standards and accounting quality. Journal of Accounting Research, 46 (3), 467-498, 2008.

BASU, S. The conservatism principle and the asymmetric timeliness of earnings. Journal of Accounting and Economics, v. 24, pp. pp. 3-37, 1997.

BECK, T.; DEMIRGÜÇ-KUNT, A.; MAKSIMOVIC, V. Financial and Legal Constraints to Firm Growth: Does Firm Size Matter? Journal of Finance, v. 60, p. 1377, 2005.

BRASIL. Lei n. 6.404, de 15/12/76. Dispõe sobre as sociedades por ações. Diário Oficial da União, 17/12/76. Disponível em: <http://www.planalto.gov.br/ccivil_03/Leis/L6404consol.htm>. Acesso em: 15/09/2013.

BRASIL. Decreto-Lei n. 1.598, de 26/12/77. Altera a legislação do imposto sobre a renda. Diário Oficial da União, 27/12/77. Disponível em: <http://www.planalto.gov.br/ccivil_03/decreto-lei/Del1598.htm>. Acesso em: 15/09/2013.

BRASIL. Lei n. 11.638, de 28/12/07. Altera e revoga dispositivos da Lei no 6.404, de 15 de dezembro de 1976, e da Lei n. 6.385, de 7 de dezembro de 1976, e estende as sociedades de grande porte disposições relativas a elaboração e divulgação de demonstrações financeiras. Diário Oficial da União, 28/12/07. Disponível em: 
<http://www.planalto.gov.br/ccivil_03/_ato2007-2010/2007/lei/111638.htm>. Acesso em: 12/09/2013.

BRASIL. Lei n. 11.941, de 27/05/09. Altera a legislação tributária federal relativa ao parcelamento ordinário de débitos tributários; concede remissão nos casos em que especifica; institui regime tributário de transição, alterando o Decreto $n^{\circ} 70.235$, de 6 de março de 1972, as Leis n's 8.212, de 24 de julho de 1991, 8.213, de 24 de julho de 1991, 8.218, de 29 de agosto de 1991, 9.249, de 26 de dezembro de 1995, 9.430, de 27 de dezembro de 1996 e dá outras providências. Diário Oficial da União, 28/05/09. Disponível em: http://www.receita.fazenda.gov.br/legislacao/Leis/2009/lei11941.htm Acesso em: 10/11/2013.

BRITO, G. A. S. Conservadorismo Contábil e o Custo do Crédito Bancário no Brasil. São Paulo, 2010. Tese (Doutorado em Controladoria e Contabilidade) - Programa de Pós-Graduação em Controladoria e Contabilidade da Faculdade de Economia, Administração e Contabilidade - Universidade de São Paulo.

BURGSTAHLER, D.; HAIL, L.; LEUZ, C. The Importance of Reporting Incentives: Earnings Management in European Private and Public Firms. The Accounting Review, v.81, p. 983-1016, 2006.

BUSHMAN, R. M. PIOTROSKI, J. D. Financial Reporting Incentives for Conservative Accounting: The Influence of Legal and Political Institutions. Journal of Accounting and Economics, 42 (1-2) 107-148, 2006.

CAIRNS, D. Degrees of compliance. Accountancy International.68-69, 1999.

COELHO, A. C. D. Qualidade informacional e conservadorismo nos resultados contábeis publicados no Brasil. São Paulo, 2007. Tese (Doutorado em Controladoria e Contabilidade) - Programa de Pós-Graduação em Ciências Contábeis, Departamento de Contabilidade e Atuária, Faculdade de Economia, Administração e Contabilidade, Universidade de São Paulo.

COMUNIDADE EUROPEIA, CE (2002). Regulamento N. ${ }^{\circ}$ 1606/2002 do Parlamento Europeu e do Conselho de 19 de Julho de 2002, Relativo à Aplicação das Normas Internacionais de Contabilidade, Jornal Oficial das Comunidades Europeias.

COSTA, F. M.; LOPES, A. B.; COSTA, A. C. O Conservadorismo em cinco países da América do Sul. Revista de Contabilidade \& Finanças. São Paulo, n. 41, p. 7-20, mai./ago. 2006. 
CHRISTENSEN, H. B.; LEE, E; WALKER, M. Incentives or Standards: What Determines Accounting Quality Changes Around IFRS Adoption? Working paper, AAA Financial Accounting and Reporting Section, 2008.

DASKE, H.; HAIL, L.; LEUZ, C.; VERDI, R. Mandatory IFRS reporting around the world: early evidence on the economic consequences. Journal of Accounting Research, v. 46, n. 5, p. 1085-1142, 2008.

DASKE, H.; HAIL, L.; LEUZ, C.; VERDI, R. Adopting a Label: Heterogeneity in the Economic Consequences Around IAS/IFRS Adoptions. Journal of Accounting Research, 51: 495-547, 2013.

DECHOW, P.; SLOAN, R; SWEENEY, A. Detecting earnings management. The Accounting Review. v. 70, n. 2, p. 193-225, 1995.

DECHOW, P., GE, W.; SCHRAND, C. Understanding earnings quality: A review of the proxies, their determinants and their consequences. Journal of Accounting and Economics, 50, 344-401, 2010.

DEMSETZ, H.; LEHN, K. The structure of corporate ownership: causes and consequences. Journal of Political Economy, 93, 1155-1177, 1985.

DYE, R.; SUNDER, S. Why Not Allow the FASB and IASB Standards to Compete in the U.S. Accounting Horizons, 15: 257 - 72, 2001.

EASLEY, D.; O'HARA, M.P. Trade Size, and Information in Securities Markets. Journal of Financial Economics. 19:69-90, 1987.

EASTON, P.; HARRIS, T. S. Earnings as an Explanatory Variable for Returns. Journal of Accounting Research, 29: 19-36, 1991.

FAN, J. P.; WONG, T.J. Corporate ownership structure and the informativeness of accounting earnings in East Asia. Journal of Accounting and Economics, 33, 401-425, 2002. 
FÁVERO, L. P. et al. Análise de dados: modelagem multivariada para tomada de decisões. Rio de Janeiro: Elsevier, 2009.

FRANCIS, J.; SCHIPPER, K. Have Financial Statement Lost Their Relevance? Journal of Accounting Research, Vol. 37, pp. 319-352, 1999.

FRANCIS, J. R.; KHURANA, I. K.; MARTIN, X.; PEREIRA, R. The Role of FirmSpecific Incentives and Country Factors in Explaining Voluntary IAS Adoptions: Evidence from Private Firms. European Accounting Review, v. 17: 2, p. 331-360, 2008.

GAIO, C. The Relative Importance of Firm and Country Characteristics for Earnings Quality around the World. European Accounting Review, 19 (4), 693-738, 2010.

GIOIElliI, S. P. O.; CARVAlHO, A. G.; SAMPAIO, J. O. Capital de Risco e Gerenciamento de Resultados em IPOs. Brazilian Business Review, vol. 10, núm. 4, out-dez, pp. 32-68, 2013.

GLOSTEN, L.; MILGROM, P. Bid, Ask, and Transaction Prices in a Specialist Market with Heterogeneously Informed Traders. Journal of Financial Economics. 13:71-100, 1985.

GONÇALVES, J. C.; BATISTA, B. L. L.; MACEDO, M. A. S.; MARQUES, J. A. V. C. Análise do impacto do processo de convergência às normas internacionais de contabilidade no Brasil: Um estudo com base na relevância da informação contábil. Revista Universo Contábil, v. 10, n. 3, p. 25-43, 2014.

GRECCO, M. C. P. O Efeito da Convergência Brasileira às IFRS no Gerenciamento de Resultados das Empresas Abertas Brasileiras não Financeiras. São Paulo, 2013. Tese (Doutorado em Administração de Empresas) - Programa de Pós-Graduação em Administração de Empresas da Universidade Presbiteriana Mackenzie.

GROSSMAN, S.; STIGLITZ, J. On the Impossibility of Informationally Efficient Markets. American Economic Review. 70:393-408, 1980.

HAIL, L.; LEUZ, C. Cost of Capital Effects and Changes in Growth Expectations around U.S. Cross-Listings, Working paper, University of Pennsylvania and University of Chicago, 2006.

HANLON, M. The persistence and pricing of earnings, accruals, and cash flows when firms have large book-tax differences. The Accounting Review, 80, 137-166, 2005. 
HAW, I. M.; HU, B.; HWANG, L. S;e WU, W. Ultimate Ownership, Income Management, and Legal and Extra-Legal Institutions. Journal of Accounting Research, 42: 423-462, 2004.

HEALY, P. M. The Effect of Bonus Schemes on Accounting Decisions. Journal of Accounting and Economics, 7: 85-107, 1985.

HOLTHAUSEN, R. W.; WATTS, R. L. The relevance of the value-relevance literature for financial accounting standard setting. Journal of Accounting \& Economics. v. 31, No 1-3, 2001.

ISIDRO, H.; RAONIC, I. Firm incentives, institutional complexity and the quality of "harmonized" accounting numbers. The International Journal of Accounting. Volume 47, Issue 4, Pages 407-436, 2012.

JOIA, R. M.; NAKAO, S. H. Adoção de IFRS e gerenciamento de resultado nas empresas brasileiras de capital aberto. Revista de Educação e Pesquisa em Contabilidade, v.8, $\mathrm{n}^{\circ}$ 1, p. 22-38, 2014.

JONES, J. J. Earnings Management During Import Relief Investigations. Journal of Accounting Research.Vol. 29, No. 2, pp. 193-228, 1991.

KANG, S.; SIVARAMAKRISHNAN, K. Issues in testing earnings management and an instrumental variable approach. Journal of Accounting Research, Oxford. v. 33, n. 2, p. 353-367, 1995.

KLANN, R. C. Gerenciamento de resultados: análise comparativa de empresas brasileiras e inglesas antes e após a adoção das IFRS. 2011. Tese (Doutorado em Ciências Contábeis e Administração) - PPGCC, Universidade Regional de Blumenau, Blumenau, 2011.

KOTHARI, S. P.; LEONE, A.; WASLEY, C. Performance matched discretionary accrual measures, Journal of Accounting and Economics, 39, 163-197, 2005.

KYLE, A. Continuous Auctions and Insider Trading. Econometrica. 53:1315-35, 1985. 
LAFOND, R.; ROYCHOWDHURY, S. Managerial ownership and accounting conservatism. Journal of Accounting Research, 46, 101-35, 2008.

LA PORTA, R.; LOPEZ-DE-SILANES, F; SHLEIFER, A. Corporate Ownership Around the World. The Journal of Finance. v. 54, n. 2, p. 471-517, 1999.

LANG, M.; LINS, K. V.; MAFFETT, M. Transparency, Liquidity, and Valuation: International Evidence on When Transparency Matters Most. Journal of Accounting Research, 50: 729-774, 2012.

LANG, M.; LINS, K. V.; MILLER, D.P. ADRs, analysts, and accuracy: does cross listing in the United States improve a firm's information environment and increase. Journal of Accounting Research, v.41, n. 2, p. 317-345, 2003.

LANG, M.; RAEDY, S.; WILSON, W. Earnings management and cross listing: Are reconciled earnings comparable to US earnings? Journal of Accounting and Economics, Elsevier, vol. 42(1-2), pages 255-283, October, 2006.

LANG, M.; J. RAEDY; M. YETMAN. How Representative Are Firms That Are Cross Listed in the United States? An Analysis of Accounting Quality. Journal of Accounting Research, 41: 363-86, 2003.

LEUZ, C. Discussion of Adrs, Analysts, and Accuracy: Does Cross-Listing in the United States Improve a Firm's Information Environment and Increase Market Value? Journal of Accounting Research, 41(2), pp. 347-62, 2003.

LEUZ, C.; NANDA, D.; WYSOCKI, P. D. Earnings management and investor protection: an international comparison. Journal of Financial Economics, 69, 505-527, 2003.

LEUZ, C.; WYSOCKI, P. Economic consequences of financial reporting and disclosure regulation: a review and suggestions for future research [Working Paper]. Social Science Research Network, Chicago, IL, USA, 2008.

LEVENTIS, S.; DIMITROPOULOS, P. E.; ANANDARAJAN, A. Loan loss provisions, earnings management and capital management under IFRS: the case of EU Commercial Banks. Journal of Financial Services Research, v. 40, n. 1, p. 103-122, 2011. 
LIMA, J. B. N. A Relevância da Informação Contábil e o Processo de Convergência para as Normas IFRS no Brasil. São Paulo, 2011. Tese (Doutorado em Controladoria e Contabilidade) - Programa de Pós-Graduação em Controladoria e Contabilidade da Faculdade de Economia, Administração e Contabilidade - Universidade de São Paulo.

LIMA, V. S. Incentivos no nível da firma e consequências econômicas da convergência ao IFRS no Brasil. São Paulo, 2011. Dissertação (Mestrado em Controladoria e Contabilidade) - Programa de Pós-Graduação em Controladoria e Contabilidade da Faculdade de Economia, Administração e Contabilidade- Universidade de São Paulo.

LOPES, A. B. A relevância da informação contábil para o mercado de capitais: o modelo de Ohlson aplicado à BOVESPA. São Paulo, 2001. Tese (Doutorado em Ciências Contábeis) - Programa de Pós-Graduação em Controladoria e Contabilidade, Faculdade de Economia, Administração e Contabilidade da Universidade de São Paulo.

LOPES, A. B; WALKER, M. Firm-Level Incentives and the Informativeness of Accounting Reports: An Experiment in Brazil. Working Paper, 2008. Disponível em SSRN:http://ssrn.com/abstract=1095781. Acesso em: dezembro de 2013.

MARTINEZ, A. L. Gerenciamento de Resultados no Brasil: um survey da literatura. Brazilian Business Review, v.10, n.4, Out-Dez, p. 1-31, 2013.

NAKAO, S. H. A Adoção de IFRS e o Legado da Conformidade Contábil-fiscal Mandatória. Ribeirão Preto, 2012. Tese de Livre Docência. Faculdade de Economia, Administração e Contabilidade de Ribeirão Preto - Universidade de São Paulo.

PAULO, E. Manipulação das informações contábeis: uma análise teórica e empírica sobre os modelos operacionais de detecção de gerenciamento de resultados. São Paulo, 2007. Tese (Doutorado em Controladoria e Contabilidade) - Programa de PósGraduação em Ciências Contábeis, Departamento de Contabilidade e Atuária, Faculdade de Economia, Administração e Contabilidade, Universidade de São Paulo.

PIMENTEL, R. C. Accounting Earnings Properties and Determinants of Earnings Response Coefficient in Brazil. São Paulo, 2009. Tese de doutorado, Programa de PósGraduação em Ciências Contábeis, Departamento de Contabilidade e Atuária, Faculdade de Economia, Administração e Contabilidade da Universidade de São Paulo. 
POWNALL, G.; SCHIPPER, K. Implications of Accounting Research for the SEC's Consideration of International Accounting Standards for U.S. Securities Offerings. Accounting Horizons: September 1999, Vol. 13, No. 3, pp. 259-280, 1999.

RANGEL, L. L.; TEIXEIRA, A. J. C. O conservadorismo contábil e o valor de mercado. In: ENCONTRO DA ASSOCIAÇÃO NACIONAL DOS PROGRAMAS DE ADMINISTRAÇÃO - ENANPAD, 27., 2003, Atibaia, SP. Curitiba: Associação Nacional dos Programas de Administração - ANPAD, 2003.

RUBIN, A. Ownership level, ownership concentration and liquidity. Journal of Financial Markets. 10, 219-248, 2007.

SANTANA, S. L. L. Planejamento Tributário e o valor da firma no mercado de capitais brasileiro. Ribeirão Preto, 2014. Dissertação (Mestrado em Controladoria e Contabilidade) - Programa de Pós-Graduação em Controladoria e Contabilidade da Faculdade de Economia, Administração e Contabilidade - Universidade de São Paulo.

SANTOS, E. S.; PONTE, V. M. R.; MAPURUNGA, P. V. R. Adoção Obrigatória do IFRS no Brasil (2010): Índice de Conformidade das Empresas com a Divulgação Requerida e Alguns Fatores Explicativos. Revista de Contabilidade e Finanças, v. 25, n. 65, p. 161-176, 2014.

SANTOS, L. P. G. dos; LIMA, I. S.; LIMA, G. A. S. F. de; FREITAS, S. C. de F. Efeito da Lei 11.638/07 sobre o conservadorismo condicional das empresas listadas BM\&FBOVESPA. Revista de Contabilidade \&. Finanças, v. 22, n. 56, p. 174-188, maio/jun./jul./ago. 2011.

SANTOS, O. M. Lobbying na Regulação Contábil e Qualidade da Informação: Evidências no Setor Petrolífero. São Paulo, 2012. Tese (Doutorado em Controladoria e Contabilidade) - Programa de Pós-Graduação em Controladoria e Contabilidade da Faculdade de Economia, Administração e Contabilidade - Universidade de São Paulo.

SCHOLES, M. S.; WOLFSON, M. A.; ERICKSON, M. MAYDEW, E. L.; SHEVLIN, T. Taxes and business strategy: a planning approach (2. ed. ed.). Upper Saddle River, New Jersey: Prentice Hall, 2002.

SILVA, R. L. M. Adoção Completa das IFRS no Brasil: Qualidade das Demonstrações Contábeis e o Custo de Capital Próprio. São Paulo, 2013. Tese (Doutorado em Controladoria e Contabilidade) - Programa de Pós-Graduação em Controladoria e Contabilidade da Faculdade de Economia, Administração e Contabilidade Universidade de São Paulo. 
SUZART, J. A. S. Informações Contábeis Governamentais e o Mercado Secundário de Títulos Públicos: um Estudo sob a Ótica da Value Relevance no Brasil. São Paulo, 2013. Tese (Doutorado em Controladoria e Contabilidade) - Programa de Pós-Graduação em Controladoria e Contabilidade da Faculdade de Economia, Administração e Contabilidade - Universidade de São Paulo.

STREET, D.; GRAY, S. Observance of International Accounting Standards: factors explaining non-compliance. ACCA Research Report 74. London, UK: Association of Chartered Certified Accountants, 2002.

TENDELOO, B. V.; VANSTRAELEN, A. Earnings management under German GAAP versus IFRS, European Accounting Review, Vol. 14, № 1, pp. 155-180, 2005.

VIEIRA, R. B. Impactos da implantação parcial das IFRS no Brasil: efeitos na qualidade das informações contábeis das empresas de capital aberto. Ribeirão Preto, 2010. Dissertação (Mestrado em Controladoria e Contabilidade) - Programa de PósGraduação em Controladoria e Contabilidade da Faculdade de Economia, Administração e Contabilidade de Ribeirão Preto - Universidade de São Paulo.

WATTS, R. Conservatism in accounting. Part I: explanations and implications. Accounting Horizons, 17, pp. 207-221, 2003.

ZÉGHAL, D.; CHTOUROU, S.; SELLAMI, Y. M. An analysis of the effect of mandatory adoption of IAS/IFRS on earnings management. Journal of International Accounting, Auditing and Taxation, v. 20, n. 2, p. 61-72, 2011.

ZENG, T. Ownership Concentration, State Ownership, and Effective Tax Rates: Evidence from China's Listed Firms. Accounting Perspectives, 9 (4), 271-289, 2011. 